\title{
Correlated evolution of nest and egg characteristics in birds
}

\section{Jenő Nagy ${ }^{\mathrm{a}}$, Mark E. Hauber ${ }^{\mathrm{b}}$, Ian R. Hartley ${ }^{\mathrm{c}}$, Mark C. Mainwaring ${ }^{\mathrm{d}}$}

${ }^{a}$ Department of Evolutionary Zoology and Human Biology, University of Debrecen, Egyetem tér 1., H-4032

Debrecen , Hungary

${ }^{b}$ Department of Evolution, Ecology, and Behavior, School of Integrative Biology, University of Illinois at Urbana-Champaign, Urbana, IL 61801, USA

${ }^{c}$ Lancaster Environment Centre, Lancaster University, Lancaster, LA1 4YQ, UK

${ }^{d}$ Division of Biological Sciences, University of Montana, Missoula, MT 59812, USA

* Correspondence: Mark C. Mainwaring, Division of Biological Sciences, University of Montana, Missoula, MT 59812, USA.

Email address: mark.mainwaring@mso.umt.edu (Mark C. Mainwaring)

Short title: Correlated evolution of birds' nests and eggs

Word count: 11,065 
Correlational selection is defined as selection for adaptive character combinations, and it therefore favours combinations of co-evolved traits via phenotypic integration. Whereas the evolution of avian nest-building and egg-laying characteristics are well understood, their correlated dynamics remain overlooked. Here, we examined patterns of correlated evolution between nest, egg, and clutch characteristics in 855 species of birds from 90 families, representing nearly $9 \%$ and 33\% of avian species- and family-level diversity. We show that the ancestral state of birds' nests was semi-open with nest sites having since become progressively more open over time. Further, nest characteristics appeared to have influenced egg-laying patterns characteristics in that whilst semi-open nests with variable clutch sizes were probably ancestral, clutch sizes have declined over evolutionary time in both open and closed nests. Ancestrally, avian eggs were also large, heavy, and either elliptic or round and there have been high transition rates from elliptic to round eggs in open nests and vice versa in closed nests. Ancestrally, both white and blue-brown eggs were laid in open nests, although pigmented eggs have transitioned more to white over time in open and closed nests, independently. We conclude that there has been a remarkable level of correlated evolution between the nest and egg characteristics of birds, which supports scenarios of correlational selection on both of these extended avian phenotypes.

Keywords:

birds

comparative analyses

correlated evolution

eggs

nests 
Evolutionary processes, such as natural and sexual selection, can affect fitness in individuals with variable traits. In some situations, correlational selection favours certain combinations of traits via phenotypic integration, which occurs when multiple functionally related traits are biologically linked and statistically correlated with each other (Sinervo \& Svensson, 2002). Selection for the optimal combination of traits favours genetic correlations that provide advantages via the formation of linkage disequilibrium at loci governing trait combinations (Hansen \& Houle, 1980). Such correlated evolution, defined as selection for adaptive character combinations, yields trait sets within species (Sinervo et al., 2001) that are seen in many contexts, including correlated evolution between personality and morphology in fish (Kern et al., 2016), maternal and their fetal phenotypes over the share of the increase in blood sugar when humans are pregnant (Haig, 1993), queens and workers over optimal sex ratios in social Hymenoptera (Ratnieks et al., 2006), coloration and ambush sites in which to catch prey (Gawryszewski et al., 2017), mating behaviours and parental care in birds (Alonzo, 2010), and parents and offspring over parental care in birds (Kölliker \& Richner, 2003). In fact, theory suggests that the evolution of food provisioning prompted an evolutionary pressure for parents to choose safer, enclosed nesting or denning sites which promoted direct competition between siblings in situ which further prompted parental food provisioning, thereby illustrating the mutual reinforcement of different types of investment (Gardner \& Smiseth, 2011). Such correlated evolutionary dynamics between successive reproductive stages are poorly understood, however, and here, we examine correlated selection on nest and egg (including clutch size) characteristics in birds, a lineage with obligate parental care for progeny.

The evolution of nest characteristics amongst birds and their non-avian ancestors remains relatively poorly understood (Collias, 1997; Hansell, 2000; Mainwaring et al., 2014), which is at least partly because nest structures, and nest construction behaviours, do not preserve well over time, including in the fossil record (Varricchio \& Jackson, 2013). Nevertheless, there is evidence from fossils that whilst the earliest dinosaurs laid eggs below ground and covered them with soil (Vila et al., 2010), non-avian theropods later evolved to lay, sometimes colourful (Wieman et al., 2018), eggs above ground (Chiappe et al., 1998; Fernández et al. 2013; Tanaka et al., 2015) so that parents might incubate and protect those eggs (Norell et al., 1995). It was only later that euornithine birds laid eggs in fully exposed nests, which is prevalent 
amongst extant birds (Tanaka et al., 2015) and such diversification enabled birds to nest in a much greater diversity of habitats and sites (Brusatte et al., 2015; Mayr, 2017).

Recent fully-inclusive, molecularly informed avian phylogenies (e.g., Jetz et al., 2012) now allow us to investigate the evolution of nest building behaviours within and among all major clades of extant birds (Fang et al., 2018). Our understanding is growing, relative to earlier, narrow taxon-sampling studies of focal families or groups that have shown, for example, that nesting in cavities evolved from simple burrowing in swallows (Winkler \& Sheldon, 1993). Similarly, the shift from nesting in cavities to building vegetative nests occurred at least three times in Neotropical ovenbirds Furnariidae (Irestedt et al., 2006), enclosed nests with roofs and a small entrance hole evolved from cavity nests in these ovenbirds (Zyskowski \& Prum, 1999), and open cup nests also evolved from enclosed nests with roofs and a small entrance hole in Australian finches (Price \& Griffiths, 2017). Meanwhile, the construction of domed nests evolved through building progressively more complex structures in the African lovebird genus Agapornis (Eberhard, 1998), whereas the evolution of domed nests in Old World babblers evolved in association with the habit of ground nesting, with species building domed nests at a lower height than species building cupshaped nests (Hall et al., 2015).

Oological evolutionary trends in birds and their ancestors also remain poorly understood because similarly to nests, thin-shelled eggs and whole clutches preserve poorly. Nevertheless, the ancestral colour of birds' eggs is thought to have been white (Kilner, 2006), although Wiemann et al. (2018) showed that the earliest of birds already had the genetic background available to colour their eggs. There is also some evidence that the eggs of near-avian dinosaurs were coloured and accordingly, the first records of the eggshell pigments protoporphyrin and biliverdin come from 66 million year-old oviraptorid Heyuannia huangi eggshells that may have been camouflaged by their blue-green colouration (Wiemann et al., 2015). Meanwhile, dinosaurs had two functioning ovaries (Norell et al., 1995) but the two extant groups of Archosauria differ because whilst crocodilians produce larger clutches of symmetrical eggs laid en masse from two functioning ovaries, birds produce many fewer and asymmetrical eggs from a single functional ovary (Grellet-Tinner et al., 2006). These evolutionary changes have been accompanied by a progressively increasing amount of parental care needed. Coloured eggs are present in most, but not all, modern avian 
lineages which build open nests, likely serving for crypsis as the eggs are vulnerable due to periods without parental guarding (Kilner, 2006). Studies examining the co-evolution of avian nest characteristics and eggshell colour have shown that in European passerines, hole nesting species have evolved more reflective eggs in the ultra- and near-violet spectra, perhaps because of an increased selection pressure for visibility in dark nesting environments and the variation in risks of brood parasitism or predation (Avilés et al., 2006; Soler et al., 2005). Meanwhile, eggshell pigment concentration is associated with nest sites and nest design, after controlling for phylogeny, in about 50 non-passerine genera (Cassey et al., 2012). Visual signalling resulting in camouflage of a clutch largely depends on eggshell colouration relative to the colour shade of the nesting background (Stoddard et al., 2017). Despite these findings, our understanding of the evolutionary transitions between co-present avian reproductive traits, including nest and eggshell diversity co-variation in particular, remains relatively poor (Hauber, 2014).

Here, we examine the evolution of nest design, egg characteristics, and also their correlated evolutionary dynamics in an already available data base (Cramps \& Simmons, 1977, 1980, 1983; Cramp, 1985, 1988, 1992; Cramp \& Perrins, 1993, 1994a, 1994b) of 855 ( 9\%) species of birds from 90 (most) families, representing 23 (most) orders. By doing so, we address a fundamental omission in our understanding of the evolutionary shifts in avian reproductive traits. For example, whereas some species build open nests, others excavate a cavity, and yet other species secondarily take over the cavities made by other species. While most nests are short-lived seasonal structures that are constructed to protect eggs, some species have nests that last and are reused for many years and sometimes even decades (Hansell, 2000). Although empirical studies provide good evidence for the current benefits of costly parental care through nest building (Hauber, 2002), much less is known about its evolutionary origins and trajectories (Collias, 1997; Hansell, 2000). Concurrently, we provide novel insights into the correlated evolution of reproductive traits, which is the result of selection for adaptive character combinations. Birds are an appropriate system in which to examine these processes because they use a more diverse range of materials to build nests of more shapes and sizes than any other taxa (Hansell, 2000; Mainwaring et al., 2014).

Here we set out to test four specific aims: first, we hypothesised that enclosed nests were the ancestral nest design (following Price \& Griffiths, 2017) and that nest sites above ground became more 
frequent over time; in turn we predicted that such shifts in nest sites have influenced the design of nests because nest sites and nest design are expected to have evolved in parallel with each other (Hall et al., 2015). Second, we hypothesised that nest sites influenced egg shape and volume as well as parental body mass (Dyke \& Kaiser, 2010), because egg shape (Duursma et al., 2018) and body mass (Martin et al., 2017) are predicted to vary with nest site. Third, we hypothesised that clutch sizes became smaller over time as part of a long-term decrease in clutch sizes evident from non-avian ancestors onwards (Brusatte et al., 2015; Mayr, 2017). Fourth, we hypothesised that as ancestral eggs were large and heavy, they have evolved to become smaller, lighter and rounder over time as well as less colourful, but more maculated, as nest sites have become more open and subtler egg forms are advantageous (Kilner, 2006; Mayr, 2017).

\section{METHODS}

\section{Nest and egg data}

We categorised the nest and egg characteristics of 855 bird species from 90 families listed in the Birds of the Western Palearctic book series (Cramps \& Simmons, 1977, 1980, 1983; Cramp, 1985, 1988, 1992; Cramp \& Perrins, 1993, 1994a, 1994b). Nest site use was quantified as either being on the ground or above ground. We consider nest design to be more complex than simply the structure of the nest itself because the location in which the nest is built strongly influences its overall characteristics as well (Mainwaring et al., 2014). For example, cup-shaped nests built by passerine birds in sparse vegetation are far more exposed to adverse weather conditions and to predators than the cup-shaped nests built by passerine birds in tree holes (von Haartman, 1957). We, therefore, combined aspects of the shape and location of birds' nests to produce a single, more biologically meaningful, nest design factor. Open nests were defined as being either cup, plate, scrape or bed nests in figure 3.2 in Hansell (2000) that were built in open locations; enclosed nests were defined as being either nests of any structure built inside holes or being enclosed nests which comprise dome, dome and tube or burrow nests built in any location; and semiopen nests were defined as cup, plate, scrape or bed nests built in enclosed locations such as in thick 
vegetation and consequently, semi-open nests represent an intermediate state between open and enclosed nests. This means, for example, that the Procellariidae (fulmars, petrels, shearwaters) building burrows in the ground were classified as being closed nesters, the Sulidae (boobies, gannets) building plate nests on ledges were open, the Charadriidae (plovers, lapwings) and Sternidae (terns) building scrape nests on the ground were open, the Sylviidae (old world warblers and allies) and the Accipitridae (hawks, eagles) building cup nests in trees or bushes and were semi-open, and the Paridae (tits) building cup nests in holes were closed. Note that whenever a species was listed as nesting in two nest site types, such as tree holes and in tree canopies in different regions, that species was classified as breeding in the nest type it most commonly uses in the Western Palearctic.

We classified egg characteristics via a combination of the descriptions in the species accounts and by subjective inspection of the plates (Cramp \& Simmons, 1977, 1980, 1983; Cramp, 1985, 1988, 1992; Cramp \& Perrins, 1993, 1994a, 1994b). Clutch sizes were provided in the book series as upper and lower average values and upper and lower range limits and here, we classified clutch sizes as the mean average of the upper and lower clutch sizes, whilst the same procedure was applied for egg weights. Egg volume was calculated by obtaining values for the length and breadth of eggs and then by using the following formula to calculate volume: volume $=0.51 \times$ length $\mathrm{x}$ breadth $^{2}$ (following Hoyt 1979). Egg shape was calculated as the egg width divided by the egg length (Biggins et al., 2018). Finally, the background colour of eggs was categorised as being brown-beige or blue-white. Because egg colouration comes from two pigments, brown protoporphyrin and blue biliverdin (Kennedy \& Vevers, 1976) and blue eggs are thought to have evolved from white eggs (Kilner, 2006), the categories of pigmented and white eggs were used in the correlative evolutionary analyses. Finally, egg maculation was coded as either being maculated or nonmaculated, with non-maculated eggs having either no or barely discernible maculation (Kilner, 2006).

We extracted the mean body mass of males and females for all species during the breeding season from the Birds of the Western Palearctic book series (Cramp \& Simmons, 1977, 1980, 1983; Cramp, 1985, 1988, 1992; Cramp \& Perrins, 1993, 1994a, 1994b), preferring estimates from the UK due to larger sample sizes. Body mass was calculated as the mean of male and female body mass, following Møller et al. (2010). 


\section{Comparative analyses}

Data management, phylogenetic generalized least squares (PGLS)/path analyses and the processing of the results were performed in R v3.5.1 (R Development Core Team, 2018). First, we investigated the association of several variables with nest design, clutch size, and egg parameters in pairwise analyses (Table 1) applying PGLS approach ['nlme' package (Pinheiro et al., 2015)]. We identified the above listed variables to be included in further analyses for which we focused mainly on the ancestral states and the correlated evolution of nest and egg characteristics, thus first we performed calculations for transition rates among the categories of nest design. Ancestral trait estimation was conducted across the phylogeny using maximum likelihood method to find the most probable ancient state of the common ancestor of all species. We also mapped nest design, nest site, egg shape and egg colouration (both background colour and maculation) on the phylogeny by applying stochastic character mapping ['phytools' package (Rewell, 2012)] simulated 1000 times. Second, we tested for correlated evolution between nest design and (1) nest site, (2) clutch size, (3) egg volume, (4) egg weight, (5) egg shape, (6) egg colour, and (7) egg maculation. These evolutionary analyses were conducted using the MultiState and Discrete modules of BayesTraits 3.0 (Pagel et al., 2004; Pagel \& Meade, 2006). The MultiState module allowed us to estimate ancestral states and transition rates among states of a trait containing a few discrete categories, using Bayesian approach, whilst the Discrete module is applicable for the estimation of transition rates of correlated evolution between a pair of traits on a phylogeny. We used the dependent model approach which assumes that the rate of changes in one trait is dependent on the state of the other trait, which has additional information compared to a simple correlative analysis estimating only the relationship between two traits, such as PGLS. Accordingly, we have binarized some of our variables listed below. We also compared each model to the independent version (null model) and used likelihood ratio tests to evaluate the differences. Significant results of these tests indicate statistical differences between the dependent and independent models (Table 2; Supplementary table 13). Phylogenetic trees were obtained from BirdTree (http://birdtree.org/). The identification of evolutionary trends in nest design and in correlated evolutionary analyses were repeated using 100 randomly selected phylogenies and the results were averaged with the 
$95 \%$ confidence intervals also calculated. These type of analyses are allowed to run using data containing some missing values for particular traits thus all of the 855 species were included.

Correlated evolutionary analyses can only be performed on binary data and so the raw values for the following variables were re-coded around the median values if they were non-binary. If we should binarize the data for the purposes of extracting the most information from the correlative and the evolutionary transition analyses, we could not have an a priori cut off point, hence the median, i.e. the lowest $50 \%$ vs. the highest $50 \%$ is the most statistically unbiased cut off for these metrics. The median clutch size across all the species in our sample set was four and so clutch sizes less than four were considered small and clutches of four or more eggs were considered large. The same procedure was applied for egg weight and egg volume and so if the values of a species were less than the median value ( $10 \mathrm{~g}$ and 9106.6 $\mathrm{mm}^{2}$, respectively) then they were coded as light and small, respectively, and if they were above the median value then they were considered heavy and large, respectively. Egg shape index was calculated as the egg width divided by the egg length (Salamon and Kenth 2017) and eggs were coded as being elliptical if the value was less than the median value of 0.73 or round if it was the same or above the median value. We also repeated these analyses setting the cut-off points to the $25^{\text {th }}$ and $75^{\text {th }}$ percentiles of each continuous variables to further evaluate the existence or deficiency of the correlated evolution between nest design and egg characteristics (see e.g. Fristoe et al. 2017).

Furthermore, a maximum clade credibility tree was created using TreeAnnotator v1.8.3. (Rambaut \& Drummond, 2006) for phylogenetic path analyses. The calculations were based on the confirmatory path analysis ['cpa' package (Bellino et al., 2015)] with the change of a simple linear regression to PGLS, allowing control for the phylogenetic history of species. This method can provide all necessary parameters for evaluating paths and executing multi-model inference (e.g. Redondo et al. 2019). Here, the sample size was 556 species after removing those with missing values. Paths were generated using the following rules: nest design (ND) is never a causal factor of any other variable, however it is indirectly affected by body mass (BM) via a direct connection including any combination of clutch size (CS), nest site (NS), egg shape (ES) or egg volume (EV) and egg background colour (EC) or egg maculation (EM). We were particularly interested in the effects of the four egg parameters, thus we included them in the path analyses separately 
avoiding overlapping effects and keeping the models simpler. All variables can act as cause and effect of each other depending on plausible mechanisms which vary among different scenarios, with an exception that nest site is never a cause of body mass (see Supplementary Material for summary and detailed explanation of accounted paths), assuming that appropriate nest sites selected for breeding are more likely to depend on the birds' size (bird perspective) than vice versa, i.e. bird size is adapted to the available nest site. Similarly, we also assumed that nest design evolved as a result of selection pressures from other traits since the design of nests reflects selective forces such as the risk of predation (Mainwaring et al. 2014). If nest design drives those traits, however, we would still be able to detect them via the correlated evolutionary analyses outlined above. The resulting 872 scenarios (218-218 with each egg parameter respectively) were compared using the C-statistic information criterion (CICc, von Hardenberg \& González-Voyer, 2013; Redondo et al. 2019).

\section{RESULTS}

\section{Nest site selection and nest design}

The ancestral state of avian nest design was most likely to have been semi-open nests (root probability $(\mathrm{rp})=0.72)$ rather than either open $(\mathrm{rp}=0.17)$ or closed nests $(\mathrm{rp}=0.11)$. There were, however, high transition rates between open and closed and also between closed and open nests (Table 3; Supplementary table 5) as illustrated by the results of stochastic character mapping in Fig. 1A. Note that transition rates refer to the overall probability of a transition from State 0 to State 1 during a given time period. Relationships between nest design and nest site selection are less clear although open nests above ground were more probably ancestral $(\mathrm{rp}=0.36)$ as illustrated in a phylogenetic context in Fig. 1B. There were also high transition rates from closed nests to open nests above ground and from closed ground nests to closed nests above ground with slightly lower intermediate transition rates in the opposite direction

(Table 3; Supplementary table 6). There were, meanwhile, intermediate transition rates from closed ground 
nests to open ground nests and from open nests above ground to open ground nests and from open ground nests to open nests above ground.

\section{Nest design and clutch sizes}

Relationships between nest design and clutch sizes showed that open nests with either small ( $\mathrm{rp}=$ $0.36,0.37,0.40$; respectively in all three analyses with different cut-off points) or large ( $\mathrm{rp}=0.31,0.40$, 0.41) clutch sizes were ancestral. There have, however, been high transition rates in both open and closed nests from small to large clutches and particularly from large to small clutches (Table 3; Supplementary table 7) thereby indicating a decline in clutch sizes in either open or closed nest design. Note that the correlated evolutionary analyses used to calculate these results differ from the analyses outlined in the section above in that these data are performed on binary data and so semi-open nests which were ancestral in the section above were combined into the same section as open nests.

\section{Nest design and egg characteristics}

The ancestral relationship between nest design and egg volume was most probably open nests with large eggs $(\mathrm{rp}=0.35,0.46,0.58)$ and is less likely to have been closed nests with large eggs $(\mathrm{rp}=0.19$, $0.29,0.32)$ or open nest with small eggs ( $\mathrm{rp}=0.05,0.24,0.31)$. For both small and large eggs, there were high transition rates from closed to open nests and much smaller transition rates from open to closed nests (Table 3; Supplementary table 8). Meanwhile, the ancestral relationship between nest design and egg weight was most probably open nests with heavy eggs $(\mathrm{rp}=0.32,0.52,0.57)$ and is slightly less likely to have been open nest with light eggs $(\mathrm{rp}=0.04,0.25,0.34)$ or closed nests with heavy eggs $(\mathrm{rp}=0.12,0.24,0.35)$. For both light and heavy eggs, there were high transition rates from closed to open nests and smaller transition rates from open to closed nests (Table 3; Supplementary table 9).

Ancestral patterns of nest design and egg shape were either elliptic $(\mathrm{rp}=0.41,0.45,0.46)$ or round eggs $(\mathrm{rp}=0.39,0.45,0.46)$, both in open nests. In open nests there were high transition rates from round to 
elliptic eggs and in closed nests, there were high transition rates from elliptic to round eggs and vice versa. There was, meanwhile, support for the evolution of egg shape independently from nest design with frequent changes between the shapes (Fig. 2A, Table 3; Supplementary table 10).

The ancestral relationship between nest design and egg colour was either open nests with white eggs $(\mathrm{rp}=0.45)$ or open nests with blue-brown eggs $(\mathrm{rp}=0.40$, for both). There were high transition rates from pigmented to white eggs in both open and closed nests and more interestingly, from white to blue-brown eggs in open nest (Fig. 2B, Table 3; Supplementary table 11).

Finally, the degree of ancestral maculation remains unclear but it was more probably maculated eggs in either open $(\mathrm{rp}=0.34)$ or closed nests $(0.25)$. There was high transition rate towards open nest in lineages with non-maculated eggs and between non-maculated and maculated eggs in closed nests (Fig. 2C, Table 3; Supplementary table 12).

\section{Determinants of egg characteristics}

We employed evolutionary path analyses to examine these relationships in further detail and we used egg shape, egg volume and egg colour characteristics as predictor variables because all variables had significant relationships in the analyses outlined above. Based on preliminary analyses, egg shape was related to egg volume, egg weight and clutch size, whilst egg volume was related to egg weight, clutch size and body mass (Table 1). Egg shape encompasses both egg width and egg length and has a relatively weak negative relationship with body mass (Supplementary fig. 1; Supplementary fig. 2). Egg shape is, however, positively associated with clutch size (Supplementary fig. 3; Supplementary fig. 4), whilst egg volume is highly positively correlated with egg weight. In addition to the above presented results, egg background colour was related to clutch size indicating that white eggs are associated with smaller clutches and maculation also had remarkable associations with nest design and nest site (Table 1).

Using them in path analyses that include body mass (Supplementary fig. 5; Supplementary fig. 6), clutch size (Supplementary fig. 7; Supplementary fig. 8), nest site selection and nest design should elucidate correlated evolutionary relationships between nest and egg characteristics. The path analyses with egg 
shape as a predictor variable suggested that parental body mass, clutch size and nest site influenced egg shape, back and forth, but that egg shape does not affect nest design directly. Also, clutch size and nest site directly influenced nest design (Table 4, Fig. 3A; Supplementary table 1). Meanwhile, the path analyses with egg volume as a predictor variable showed that clutch size, parental body mass and nest site influenced egg volume and that egg volume influenced nest design directly (Table 5, fig. 3B; Supplementary table 2).

The path analyses with egg background colour as a predictor variable revealed that clutch size had a key role in determining body mass, egg background colour, nest site and nest design directly. However, egg background colour has a great impact on nest design (Table 6, Fig. 3C; Supplementary table 3). Although clutch size had direct effect on body mass, nest site selection and egg maculation in the path analyses with maculation as predictor variable, maculation was more likely influenced by body mass and nest site selection and maculation also influenced nest design directly (Table 7, Fig. 3D; Supplementary table 4).

\section{DISCUSSION}

We have used directional phylogenetic estimation techniques and evolutionary path analyses to establish patterns and to demonstrate several novel insights into the correlated evolutionary transition dynamics of variation in nest and egg characteristics in birds. First, semi-open nests appeared to be the ancestral nest type, which goes against our first prediction that enclosed nests would be ancestral (Price \& Griffiths, 2017). Meanwhile, although there have been multiple evolutionary shifts between nest types, there is strong evidence that nest sites determine nest design which does agree with our first prediction. Second, we found that nest sites affect both the shape and volume of eggs, as well as parental body mass, which agrees with our second prediction, and shows that the body mass of parents influences both the volume and the shape of extant bird species' eggs, in agreement with Stoddard et al. (2017). Third, nest characteristics influence clutch sizes because as nest sites have evolved to be in increasingly open locations, clutch sizes have become smaller in agreement with our third prediction because there has been a long-term decrease in clutch sizes from the dinosaurs through to modern extant birds (Brusatte et al., 2015; Mayr, 2017). Fourth, 
ancestral eggs were likely large, heavy and elliptical but they have evolved to become smaller, lighter and rounder over time, which agrees with our fourth prediction because eggs were thought have become smaller, lighter and rounder as nest sites became more open and thus exposed over time. Meanwhile, the laying of either white or blue-brown eggs in open nests was probably ancestral but the eggs transitioned to become more white over time; finally, the degree of ancestral maculation is unclear, but more certain is that the degree of maculation of eggs has frequently switched between open and closed nests and nests were less likely to become open with immaculate eggs.

\section{Nest site use and nest design}

The ancestral state of nest design in the studied set of birds from the Western Palearctic appears to have been semi-open nests, which contrasts with the finding that enclosed nests were ancestral in Australian finches (Price \& Griffiths, 2017). Our dataset and that of Price and Griffiths (2017) do not contain any overlapping species and a root probability value of 0.72 suggests we can be confident in our findings. These differences are presumably explained either by the contrasting environmental conditions in which the two studies were performed, with ambient temperatures in Australia being much higher than Europe, because enclosed nests buffer offspring against adverse environmental conditions (Martin et al., 2017), or the inclusion of a substantially broader range of species in our study. We also found strong evidence that nest design is influenced by the nest site with closed nests being more commonly found on the ground than above ground and open nests being more commonly found above ground than on the ground (Figs. 1 and Table 3). This pattern agrees with the only two previous studies to have examined relationships between nest sites and nest design. In the first study it was shown that nest design does vary predictably in relation to nest site across the entire avian phylogeny even though the two characters had disparate evolutionary trajectories (Fang et al., 2018). In the second, meanwhile, it was shown that in Old World Babblers, those species building domed nests bred at lower heights than taxa building open nests (Hall et al., 2015). High transition rates from closed to open nests above ground support the idea that open nests have become more 
prevalent over time as birds' nest sites have diversified (Collias, 1997). More broadly, it strongly suggests that the location in which nests are built determine their design.

\section{Determinants of egg shape and volume}

Nest sites affect both the shape and volume of eggs, as well as parental body mass, which in turn suggests that the body mass of parents influences the shape and volume of eggs. This supports a recent study which showed that egg shape in more than 1400 bird species worldwide was primarily determined by the adults' adaptations to flight (Stoddard et al., 2017; also see Shatkovska et al. 2018; Birkhead et al. 2019). We found that nest characteristics also influenced egg shape because whilst elliptic or round eggs in (semi) open nests were ancestral, eggs have evolved to become progressively rounder over time, probably in enclosed nests, but changed the other way around in open nests. The evolution of rounder eggs in enclosed nests may be in contrast with a general trend towards eggs evolving to be less round and more elongated in extant birds and their dinosaurian ancestors (Deeming \& Ruta, 2014). It also agrees with a study of Australian passerines where less rounded eggs were laid in enclosed nests (Duursma et al., 2018), which means that we have provided good evidence that egg shape is determined by nest characteristics. The evolution of egg size also differs in relation to nest design because they have become smaller over time. As species building open nests are larger in body size than species building enclosed nests (Martin et al., 2017), then this may well explain why egg sizes are particularly smaller in enclosed nests.

\section{Nest design and clutch sizes}

We also found evidence of correlated evolution between nest characteristics and clutch sizes because whilst (semi) open nests with either large or small clutch sizes were ancestral, clutch sizes have declined in open nests but have remained unchanged in enclosed nests over time. In enclosed nests, however, there have been high transition rates between large and small clutches and also between small and large clutches. The evolutionary decline in clutch sizes amongst extant birds in open nests reflects a 
trend that has been evident since the time of their dinosaurian ancestors (Grellet-Trinner et al., 2006). Ever since the dinosaurs shifted from laying their eggs below ground to above ground, the nest sites of non-avian ancestors and subsequent birds have become increasingly exposed (Tanaka et al., 2015) and particularly so during the radiative expansion of the passerines (Mayr, 2017). Eggs have thus become more exposed and more vulnerable to predators and parasites over evolutionary timescales; in response, in life history terms, this means that birds are investing fewer resources in a given nest as the risk of nest failure has increased over time (Lack, 1967). Smaller clutch sizes might also represent a trade-off against increased amount of costly parental care needed per chick particularly with the shift to altricial species whose offspring are entirely dependent on their parents not only during incubation but also after hatching (Collias, 1997).

\section{Nest design and egg characteristics}

The characteristics of eggs all evolved in a similar manner because whilst large and heavy eggs were ancestral, the eggs of birds have evolved to become smaller, lighter and rounder over time. Whilst the ancestral shape of eggs was unclear, there has been a trend towards eggs becoming rounder which may be in contrast with the general trend of eggs becoming less rounded over time in birds and their dinosaurian ancestors (Norell et al., 1995; Grellet-Trinner et al., 2006; Deeming \& Ruta, 2014). The decrease in egg weight over time likely reflects an evolutionary pattern of egg masses being negatively related to brood sizes (Lack, 1967). This nevertheless means that further studies are required to examine the evolution of egg shape in birds and in particular, studies that examine how egg shape varies in relation to the amount and type of parental care provided might prove insightful. The eggs of extant birds are smaller and lighter than those of the non-avian ancestors, which is a pattern that probably either reflects the decrease in body sizes of females or the associated decline in nest sizes (Collias, 1997) although we found little evidence of strong directional changes between small and large eggs (Supplementary fig 4) and light and heavy eggs (Supplementary fig 5) in our study. Passerines are amongst the most mobile birds and so as egg shape is largely determined by adaptations to flight (Stoddard et al., 2017) then the proliferation of passerines has presumably resulted in the evolution of smaller eggs over time in birds. However, several recent studies 
have shown that the pyriform shaped eggs of cliff-nesting seabirds have evolved to remain stable on their precarious nesting sites (Birkhead et al., 2018, 2019; Hays \& Hauber, 2018) which suggest that egg shape can evolve in parallel with the vulnerability of nest sites. These conflicting findings only serve to highlight the need for broader phylogenetic studies to examine the evolution of egg shape in extant birds and possibly even their dinosaurian relatives.

Egg colouration has varied dynamically over evolutionary time because whilst the ancestral background colour of eggs was either brown or white, there has been a trend towards eggs becoming whiter over time. A phylogenetic analysis of eggshell colouration (Kilner, 2006) concluded that the ancestral egg colour of extant birds was white and whilst the earliest dinosaurs were thought to have laid white eggs below ground (Grellet-Trinner et al., 2006), recent studies have shown that later dinosaurs evolved to lay colourful and maculated eggs above ground where parents could incubate and protect them from both predators and parasites (Wiemann et al., 2015, 2018). Our results also support these findings. Grassland vegetation began to appear ever more prominently in the Miocene (de Menocal, 2004; Bonnefille, 2010). This means that birds, including the Western Palearctic species analysed here, would have inhabited increasingly enclosed habitats which would have meant that nests were in located in increasingly more enclosed nests sites that were surrounded by vegetation, suggesting that white and/or lighter coloured eggshells would not have been as obvious to predators as they would have been in more exposed locations before grassland vegetation appeared. Meanwhile, the degree of ancestral maculation is unclear and subsequent trends have seen eggs switch in roughly equal measure from maculated to non-maculated and vice versa in both open and enclosed nests. The only exception is the lower transitioning of nests with immaculate eggs to open nests. This means that no strongly consistent evolutionary relationships are apparent and so further studies could usefully examine the selective pressures causing egg maculation to be gained and lost in birds numerous times in a seemingly inconsistent manner.

\section{Conclusions}


We have shown that the correlated evolutionary dynamics of the nest and egg characteristics of

birds vary dramatically over temporal timescales in a complex manner, and our findings have important implications for our understanding of avian reproduction. First, nest design is strongly influenced by the nest site and further studies could usefully examine the correlated evolution of nest sites and nest design in greater detail than was possible here. Second, nest sites on the ground and above the ground have been used over time and studies could usefully explore the consequences for reproductive investment as nest sites diversified. Third, the evolution of egg characteristics sometimes varied depending on nest design with, for example, eggs either evolving from being elliptic to round or from round to elliptic in open nests but only from elliptic to round in enclosed nests. Not all egg characteristics, however, vary in a predictable manner in relation to nest design, though, because whilst egg shape diverged in open and enclosed nests, neither the background colour of eggs nor their degree of maculation varied between the two nest types. Our results show that the nests and eggs of the studied birds have evolved in association with traits within each other in a complex manner. More broadly, our analyses suggest that nest and egg traits are sometimes phenotypically integrated in birds and, thus, that correlated selection acts on those evolved trait combinations.

\section{Acknowledgements}

\section{Supplementary Material}

Supplementary material associated with this article is available in the online version, at. 


\section{References}

Alonzo, S. H. (2010). Social and coevolutionary feedbacks between mating and parental investment. Trends in Ecology and Evolution, 25, 99-108.

Avilés, J. M., Soler, J. J., \& Pérez-Contreras, T. (2006). Dark nests and egg colour in birds: a possible functional role of ultraviolet reflectance in egg detectability. Proceedings of the Royal Society of London B, 273, 2821-2829.

Bellino, A., Baldantoni, D., de Nicola, F., Iovieno, P., Zaccardelli, M., \& Alfani, A. (2015). Compost amendments in agricultural ecosystems: confirmatory path analysis to clarify the effects on soil chemical and biological properties. Journal of Agricultural Science, 153, 282-295.

Biggins, J. D., Thompson, J. E., \& Birkhead, T. R. (2018). Accurately quantifying the shape of birds' eggs. Ecology and Evolution, 8, 9728-9738.

Birkhead, T. R., Thompson, J. E., Biggins, J. D., \& Montgomerie, R. (2019). The evolution of egg shape in shape in birds: selection during the incubation period. Ibis, 161, 605-618.

Birkhead, T. R., Thompson, J. E., Montgomerie, R., (2018). The pyriform egg of the Common Murre (Uria aalgae) is more stable on sloping surfaces. Auk, 135, 1020-1032.

Bonnefille, R. (2010). Cenozoic vegetation, climate change and hominid evolution in tropical Africa. Global and Planetary Change, 72, 390-411.

Brusatte, S. L., O’Connor, J. K., \& Jarvis, E. D. (2015). The origin and diversification of birds. Current Biology, 25, R888-R898.

Cassey, P., Thomas, G. H., Portugal, S. J., Maurer, G., Hauber, M. E., Grim, T., Lovell, P. G., \& Mikšík, I. (2012). Why are birds' eggs colourful? Eggshell pigments co-vary with life-history and nesting ecology among British breeding nonpasserine birds. Biological Journal of the Linnean Society, 106, 657-672.

Chiappe, L. M., Coria, R. A., Dingus, L., Jackson, F., Chinsamy, A., \& Fox, M. (1998). Sauropod dinosaur embryos from the late Cretaceous of Patagonia. Nature, 396, 258-261.

Collias, N. E. (1997). On the origin and evolution of nest building by passerine birds. Condor, 99, 253-270.

Cramp, S. (1985). The birds of the Western Palearctic, Volume 4: Terns to Woodpeckers. Oxford: Oxford University Press.

Cramp, S. (1988). The birds of the Western Palearctic, Volume 5: Tyrant Flycatchers to Thrushes. Oxford: Oxford University Press.

Cramp, S. (1992). The birds of the Western Palearctic, Volume 6: Warblers. Oxford: Oxford University Press.

Cramp, S., \& Perrins, C. M. (1993). The birds of the Western Palearctic, Volume 7: Flycatchers to Shrikes. Oxford: Oxford University Press.

Cramp, S., \& Perrins, C. M. (1994a). The birds of the Western Palearctic, Volume 8: Crows to Finches. Oxford: Oxford University Press. 
Cramp, S., \& Perrins, C. M. (1994b). The birds of the Western Palearctic, Volume 9: Buntings and New World Warblers. Oxford: Oxford University Press.

Cramp, S., \& Simmons, K. E. L. (1977). The birds of the Western Palearctic, Volume 1: Ostrich to Ducks. Oxford: Oxford University Press.

Cramp, S., \& Simmons, K. E. L. (1980). The birds of the Western Palearctic, Volume 2: Hawks to Bustards. Oxford: Oxford University Press.

Cramp, S., \& Simmons, K. E. L. (1983). The birds of the Western Palearctic, Volume 3: Waders to Gulls. Oxford: Oxford University Press.

Deeming, D. C., \& Ruta, M.( 2014). Egg shape changes at the theropod-bird transition, and a morphometric study of amniote eggs. Royal Society Open Science. 1, 140311.

deMenocal, P. B. (2004). African climate change and faunal evolution during the Pliocene-Pleistocene. Earth and Planetary Science Letters, 220, 3-24.

Duursma, D. E., Gallagher, R. V., Price, J. J., \& Griffiths, S.C. (2018). Variation in avian egg shape and nest structure is explained by climatic conditions. Scientific Reports, 8, 4141 .

Dyke, C. T., \& Kaiser, D. (2010). Cracking a developmental constraint: egg size and bird evolution. Records of the Australian Museum. 62:207-216.

Eberhard, J. R. (1998). Evolution of nest-building behaviour in Agapornis parrots. Auk, 115, 455-464.

Fang, Y. T., Tuanum, M. N., \& Hung, C. M. (2018). Asynchronous evolution of interdependent nest characters across the avian phylogeny. Nature Communications, 9, 1863.

Fernández, M. S., García, R. A., Fiorelli, L., Scolaro, A., Salvador, R. B., Cotaro, C. N., Kaiser, G. W., \& Dyke, G. J. (2013). A large accumulation of avian eggs from the Late Cretaceous of Patagonia (Argentina) reveals a novel nesting strategy in Mesozoic birds. PLoS ONE, 8, e61030.

Fristoe, T. S., Iwaniuk, A. N., \& Botero, C. A. (2017). Big brains stabilize populations and facilitate colonization of variable habitats in birds. Nature Ecology \& Evolution, 1, 1706-1715.

Gardner, A., \& Smiseth, P. T. (2011). Evolution of parental care driven by mutual reinforcement of parental food provisioning and sibling competition. Proceedings of the Royal Society of London B, 278, 196-203.

Gawryszewski, F. M., Calero-Torralbo, M. A., Gillespie, R. G., Rodríguez-Gironés, M. A., \& Herberstein, M. E. (2017). Correlated evolution between coloration and ambush site in predators with visual prey lures. Evolution 71, $2010-2021$.

Grellet-Tinner, G., Chiappe, L., Norell, M., \& Bottjer, D. (2006). Dinosaur eggs and nesting behaviours: A paleobiological investigation. Palaeogeography, Palaeoclimatology, 232, 294-321.

Haig, D. (1993). Genetic conflicts in human pregnancy. Quarterly Review of Biology, 68, 495-532.

Hall, Z. J., Street, S. E., Auty, S., \& Healy, S. D. (2015). The coevolution of building nests on the ground and domed nests in Timaliidae. Auk, 132, 584-593. 
Hansell, M. H. (2000). Bird nests and construction behaviour. Cambridge: Cambridge University Press.

Hansen, T. F., \& Houle, D. (1980). Evolvability, stabilizing selection, and the problem of stasis. In M. Pigliucci, \& K. Preston (Eds.), The evolutionary biology of complex phenotypes (pp. 130-150). Oxford: Oxford University Press.

Hauber, M. E. (2002). Is reduced clutch size a cost of parental care in Eastern Phoebes (Sayornis phoebe)? Behavioural Ecology and Sociobiology, 51, 503-509.

Hauber, M. E. (2014). The book of eggs. Chicago: Chicago University Press.

Hays, I. R., \& Hauber, M. E. (2018). How the egg rolls: a morphological analysis of avian egg shape in the context of displacement dynamics. Journal of Experimental Biology, 00, 000-000.

von Haartman, L. (1957). Adaptation in hole-nesting birds. Evolution, 11, 339-347.

von Hardenberg, A., \& González-Voyer, A. (2013). Disentangling evolutionary cause-effect relationships with phylogenetic confirmatory path analysis. Evolution, 67, 378-387.

Hoyt, D. (1979). Practical methods of estimating volume and fresh weight of bird eggs. Auk, 96: 73-77.

Irestedt, M., Fjeldså, F., \& Ericson, P. G. P. (2006). Evolution of the ovenbird-woodcreeper assemblage (Aves: Furnariidae)Major shifts in nest architecture and adaptive radiation. Journal of Avian Biology, 37, 260-272.

Jetz, W., Thomas, G. H., Joy, J. B., Hartmann, K., \& Mooers, A. O. (2012). The global diversity of birds in space and time. Nature, 491, 444-448.

Kennedy, G. Y., \& Vevers, H. G. (1976). Survey of avian eggshell pigments. Comparative Biochemistry and Physiology BBiochemistry \& Molecular Biology, 55, 117-123.

Kern, E. M. A., Robinson, D., Gass, E., Godwin, J., \& Langerhans, R. B. (2016). Correlated evolution of personality, morphology and performance. Animal Behaviour, 117, 79-86.

Kilner, R. M. (2006). The evolution of egg colour and patterning in birds. Biological Reviews, 81, 383-406.

Kölliker, M., \& Richner, H. (2003). Parent-offspring conflict and the genetics of offspring solicitation and parental response. Animal Behaviour, 62, 395-407.

Lack, D. (1967). The significance of clutch size in waterfowl. Wildfowl, 19, 67-69.

Mainwaring, M. C, Hartley, I. R., Lambrechts, M. M., \& Deeming, D. C. (2014). The design and function of birds' nests. Ecology and Evolution, 4, 3909-3928.

Martin, T. E., Boyce, A. J., Fierro-Calderón, K., Mitchell, A. E., Armstad, C. E., Mouton, J. C., \& Evertius, B. S. E. (2017). Enclosed nests may provide greater thermal than nest predation benefits compared with open nests across latitudes. Functional Ecology, 31, 1231-1240.

Mayr, G. (2017). Evolution of avian breeding strategies and its relation to the habitat preferences of Mesozoic birds. Evolutionary Ecology, 31, 131-141.

Møller, A. P., Soler, J. J., \& Vivaldi, M. M. (2010). Spatial heterogeneity in distribution and ecology of Western Palearctic birds. Ecology, 91, 2769-2782. 
Norell, M. A., Clark, J. M., Chiappe, L. M., \& Dashzeveg, D. (1995). A nesting dinosaur. Nature, 378, 774-776.

Pagel, M., \& Meade, A. (2006). Bayesian analysis of correlated evolution of discrete characters by reversible-jump Markov chain Monte Carlo. American Naturalist, 167, 808-825.

Pagel, M., Meade, A., \& Barker, D. (2004). Bayesian estimation of ancestral character states on phylogenies. Systematic Biology, $53,673-684$.

Pinheiro, J., Bates, D., DebRoy, S., Sarkar, D., \& R Development Core Team. (2015). nlme: linear and nonlinear mixed effects models. R package version 3.1-121. URL: http://CRAN.R-project.org/package=nlme/.

Price, J. J, \& Griffiths, S. D. (2017). Open cup nests evolved from roofed nests in the early passerines. Proceedings of the Royal Society of London B, 284, 20162708.

R Development Core Team. (2016). R: A language and environment for statistical computing. R Foundation for Statistical Computing, Vienna, Austria. URL: http://www.R-project.org/.

Rambaut, A., \& Drummond, A. J. (2006). TreeAnnotator v1.8.3. University of Edinburgh, Edinburgh, UK. URL: http://beast.bio.ed.ac.uk/treeannotator/.

Ratnieks, F. L. W., Foster, K. R., \& Wenseleers, T. (2006). Conflict resolution in insect societies. Annual Review of Entomology, $51,581-608$.

Redondo, T., Romero, J. M., Díaz-Delgado, R., \& Nagy, J. (2019). Broodmate aggression and life history variation in accipitrid birds of prey. Ecology and Evolution, DOI: https://doi.org/10.1002/ece3.5466.

Revell, L. J. (2012). phytools: An R package for phylogenetic comparative biology (and other things). Methods in Ecology and Evolution, 3, 217-223.

Salamon, A., \& Kent, J. P. (2017). Egg shape is constrained more by width than length, evidence from double-yolked duck eggs. International Journal of Poultry Science, 16, 387-392.

Shatkovska, O. V., Ghazali, M., Mytiai, I. S., \& Druz, N. (2018). Size and shape correlation of birds' pelvis and egg: Impact of developmental mode, habitat, and phylogeny. Journal of Morphology, 279, 1590-1602.

Sinervo, B., Bleay, C., \& Adamopoulou, C. (2001). Social causes of selection and the resolution of a heritable throat color polymorphism in a lizard. Evolution, 55, 2040-2052.

Sinervo, B., Svensson, E. I. (2002). Correlational selection and the evolution of genomic architecture. Heredity, 89, 329-338.

Soler, J. J., Moreno, J., Avilés, J. M., \& Møller, A. P. (2005). Blue and green egg-color intensity is associated with parental effort and mating system in passerines: support for the sexual selection hypothesis. Evolution, 59, 636-644.

Stoddard, M. C., Yong, E. H., Akkaynak, D., Sheard, C., Tobias, J. A., \& Mahadevan, L. (2017). Avian egg shape: Form, function and evolution. Science, 6344, 1249-1254.

Tanaka, K., Zelenitsky, D. K., \& Therrien, F. (2015). Eggshell porosity provides insight on evolution of nesting in dinosaurs. PLoS ONE, 10, e0142829. 
Varricchio, D. J., \& Jackson, F. D. (2013). Reproduction in Mesozoic birds and evolution of the modern avian reproductive mode. $A u k, 133,654-684$.

Vila, B., Galobart, A., Oms, O., Poza, B., \& Bravo, A. M. (2010). Assessing the nesting strategies of Late Cretaceous titanosaurs: 3-D clutch geometry from a new megaloolithid eggsite. Lethaia, 43, 197-208.

Wiemann, J., Yang, T-R., \& Norell, M. A. (2018). Dinosaur egg colour had a single evolutionary origin. Nature, 563, 555-558.

Wiemann, J., Yang, T-R., Sander, P. N. N., Schneider, M., Engeser, M., Kath-Sachorr, S., .Müller, C. E., \& Sander, P. M. (2015). The blue-green eggs of dinosaurs: how fossil metabolites provide insights into the evolution of bird reproduction. PeerJ, $3, \mathrm{e} 1323$.

Winkler, D. W., \& Sheldon, F. H. (1993). Evolution of nest construction in swallows (Hirundinidae) - a molecular phylogenetic perspective. Proceedings of the National Academy of Sciences of the United States of America, 90, 5705-5707.

Zyskowski, K., \& Prum, R. O. (1999). Phylogenetic analysis of the nest architecture of neotropical oven birds (Furnariidae). Auk, 116, 891-911. 


\section{Table 1}

621 Associations among variables used in this study. $\lambda$ values and estimated parameter $(\beta)$ followed by p value in parentheses are exclusively shown for significant results, extracted from PGLS analyses. The name of the groups with $\mathrm{p}<0.05$ is indicated for each categorical variable. Asterisk $(*)$ indicates marginal $(\mathrm{p}<$ 623 0.1) relationship.

\begin{tabular}{|c|c|c|c|c|c|c|c|c|c|}
\hline & \multicolumn{2}{|r|}{ Nest } & \multicolumn{5}{|c|}{ Egg } & \multirow[b]{2}{*}{ Clutch size } & \multirow[b]{2}{*}{ Body mass } \\
\hline & design & site & shape & volume & weight & $\begin{array}{c}\begin{array}{c}\text { background } \\
\text { colour }\end{array} \\
\end{array}$ & maculation & & \\
\hline Nest design & & $\begin{array}{l}\lambda: 0.94 \\
\text { ground hole/cavity: } \boldsymbol{\beta}=- \\
\mathbf{1 . 0 7}(<\mathbf{0 . 0 0 1}) \\
\text { ledge: } \boldsymbol{\beta}=\mathbf{- 0 . 4 2}(<\mathbf{0 . 0 0 1}) \\
\text { tree hole/cavity: } \boldsymbol{\beta}=- \\
\mathbf{1 . 0 4}(<\mathbf{0 . 0 0 1}) \\
\text { wall: } \boldsymbol{\beta}=\mathbf{- 0 . 5 2}(<\mathbf{0 . 0 1})\end{array}$ & $\begin{array}{l}\lambda: 0.98 \\
\text { open: } \boldsymbol{\beta}=\mathbf{- 0 . 0 2} \\
(<\mathbf{0 . 0 1 )} \\
\text { semi-open: } \beta= \\
-0.01(*)\end{array}$ & $\begin{array}{l}\lambda: 0.95 \\
\text { open: } \beta=\mathbf{1 8 9 8 8 . 4 7} \\
(<\mathbf{0 . 0 0 1 )}\end{array}$ & $\begin{array}{l}\lambda: 0.95 \\
\text { open: } \beta=\mathbf{2 1 . 4 1} \\
(<\mathbf{0 . 0 0 1 )}\end{array}$ & $\lambda: 0.69 *$ & $\lambda: 0.96$ & $\begin{array}{l}\lambda: 0.96 \\
\text { open: } \boldsymbol{\beta}=\mathbf{- 0 . 9 7} \\
(<\mathbf{0 . 0 0 1 )} \\
\text { semi-open: } \boldsymbol{\beta}=\mathbf{-} \\
\mathbf{0 . 4 8}(\mathbf{0 . 0 1})\end{array}$ & $\lambda: 1.00$ \\
\hline Nest site & & & $\lambda: 0.99$ & $\lambda: 0.96$ & $\lambda: 0.95$ & $\lambda: 0.72 *$ & $\lambda: 0.96$ & $\lambda: 0.95 *$ & $\begin{array}{l}\lambda: 1.00 \\
\text { tree/bush: } \boldsymbol{\beta}=\mathbf{- 1 3 2 3 . 6 5} \\
(\mathbf{0 . 0 3 )} \\
\text { ground: } \beta=-1073.40 \\
(*) \\
\text { ground hole/cavity: } \beta= \\
-1320.29(*) \\
\text { tree hole/cavity: } \beta=- \\
1183.76(*)\end{array}$ \\
\hline Egg shape & & & & $\begin{array}{l}\lambda: 0.98 \\
\boldsymbol{\beta}=\sim \mathbf{0}(\mathbf{0 . 0 0 1})\end{array}$ & $\begin{array}{l}\lambda: 0.98 \\
\boldsymbol{\beta}=\sim \mathbf{0}(<\mathbf{0 . 0 0 1})\end{array}$ & $\lambda: 0.71$ & $\lambda: 0.99$ & $\begin{array}{l}\lambda: 0.95 \\
\boldsymbol{\beta}=\mathbf{3 . 7 2}(<\mathbf{0 . 0 1})\end{array}$ & $\lambda: 0.99 *$ \\
\hline Egg volume & & & & & $\begin{array}{l}\lambda: 0.01 \\
\beta=919.42 \\
(<0.001)\end{array}$ & $\lambda: 0.71$ & $\lambda: 0.96$ & $\begin{array}{l}\lambda: 0.95 \\
\boldsymbol{\beta}=\sim \mathbf{0}(<\mathbf{0 . 0 0 1})\end{array}$ & $\begin{array}{l}\lambda: 0.96 \\
\boldsymbol{\beta}=\mathbf{2 . 9 7}(<\mathbf{0 . 0 0 1})\end{array}$ \\
\hline Egg weight & & & & & & $\lambda: 0.72$ & $\lambda: 0.96$ & $\begin{array}{l}\lambda: 0.95 \\
\boldsymbol{\beta}=\mathbf{- 0 . 0 1}(<\mathbf{0 . 0 0 1})\end{array}$ & $\begin{array}{l}\lambda: 0.96 \\
\boldsymbol{\beta}=\mathbf{0 . 0 0 3}(<\mathbf{0 . 0 0 1})\end{array}$ \\
\hline $\begin{array}{l}\text { Egg background } \\
\text { colour }\end{array}$ & & & & & & & $\lambda: 0.71$ & $\begin{array}{l}\lambda: 0.96 \\
\text { white: } \boldsymbol{\beta}=\mathbf{- 0 . 2 9} \\
(\mathbf{0 . 0 2})\end{array}$ & $\lambda: 0.71$ \\
\hline Egg maculation & & & & & & & & $\lambda: 0.95$ & $\lambda: 0.97$ \\
\hline $\begin{array}{l}\text { Clutch size } \\
\text { Body mass }\end{array}$ & & & & & & & & & $\lambda: 0.95$ \\
\hline
\end{tabular}




\begin{tabular}{|c|c|c|c|c|c|c|}
\hline \multirow[t]{2}{*}{ Traits } & \multicolumn{4}{|c|}{ Number of cases with significant support } & \multirow[t]{2}{*}{ Probability } & \multirow[t]{2}{*}{ Correlation } \\
\hline & Cut-off point* & Total & Dependent & Independent & & \\
\hline \multirow[t]{2}{*}{ Nest design $\sim$ Clutch size } & $25^{\text {th }}$ & 49 & 33 & 16 & 0.67 & dependent \\
\hline & $50^{\text {th }}$ & 98 & 63 & 35 & 0.64 & dependent \\
\hline \multirow[t]{3}{*}{ Nest design $\sim$ Egg shape } & $25^{\text {th }}$ & 80 & 39 & 41 & 0.49 & independent \\
\hline & $50^{\text {th }}$ & 37 & 10 & 27 & 0.27 & independent \\
\hline & $75^{\text {th }}$ & 100 & 70 & 30 & 0.70 & dependent \\
\hline \multirow{2}{*}{ Nest design $\sim$ Egg volume } & $50^{\text {th }}$ & 100 & 60 & 40 & 0.6 & dependent \\
\hline & $75^{\text {th }}$ & 91 & 83 & 8 & 0.91 & dependent \\
\hline \multirow[t]{3}{*}{ Nest design $\sim$ Egg weight } & $25^{\text {th }}$ & 92 & 78 & 14 & 0.85 & dependent \\
\hline & $50^{\text {th }}$ & 100 & 69 & 31 & 0.69 & dependent \\
\hline & $75^{\text {th }}$ & 92 & 80 & 12 & 0.87 & dependent \\
\hline Nest design $\sim$ Egg background colour & & 90 & 66 & 24 & 0.73 & dependent \\
\hline Nest design $\sim$ Egg maculation & & 96 & 77 & 19 & 0.80 & dependent \\
\hline
\end{tabular}

Table 2

Comparison of dependent and independent models to evaluating the correlated evolution of traits. Better fitting models have higher log-likelihood values. Significant likelihood ratios (LR) denote true dependence or independence in the evolution of the traits. Thus we provided the proportion of dependent models to the number of models in a subset with significant support out of the total number of estimations with 100 different phylogenetic trees. We considered the correlated evolution of traits more likely to be dependent if more than 50\% of models were dependent. (See Supplementary table 13 for the full list of models with loglikelihood, LR and $p$ values.).

\footnotetext{
* Percentiles for continuous variables (clutch size and egg characteristics)
} 
Table 3

The averaged evolutionary transition rates (with 95\% confidence intervals) between open nests, semi-open nests, and closed nests in 855 species of birds (first row) and between states of trait pairs (rest). Cut-off points for continuous traits are shown as $25^{\text {th }}, 50^{\text {th }}$ and $75^{\text {th }}$. Higher transition rates $(>40)$ are indicated with red and blue colour represents intermediate values (from 20 to 40), in both text and figures.

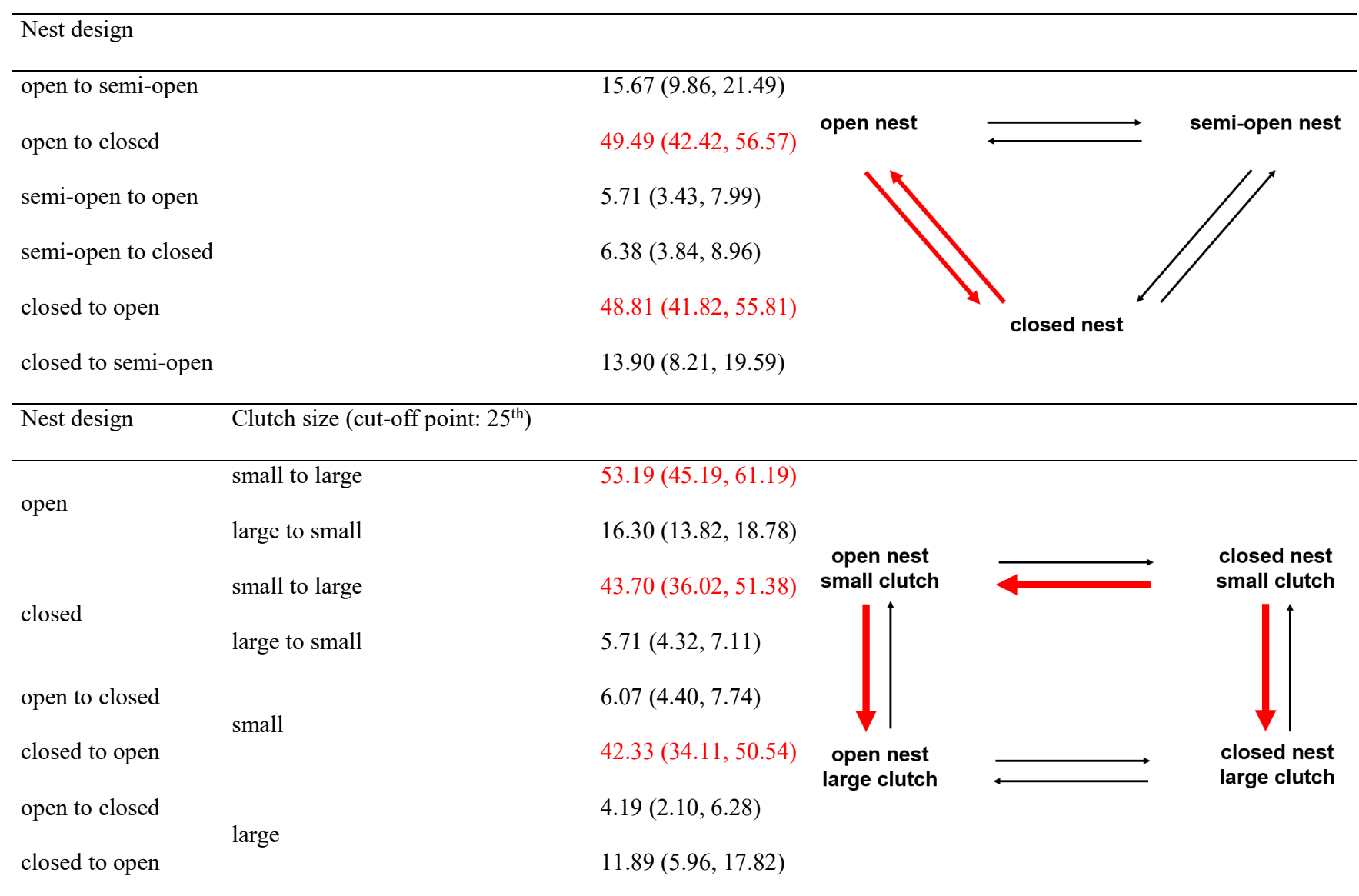

Clutch size (cut-off point: $50^{\text {th }}$ )

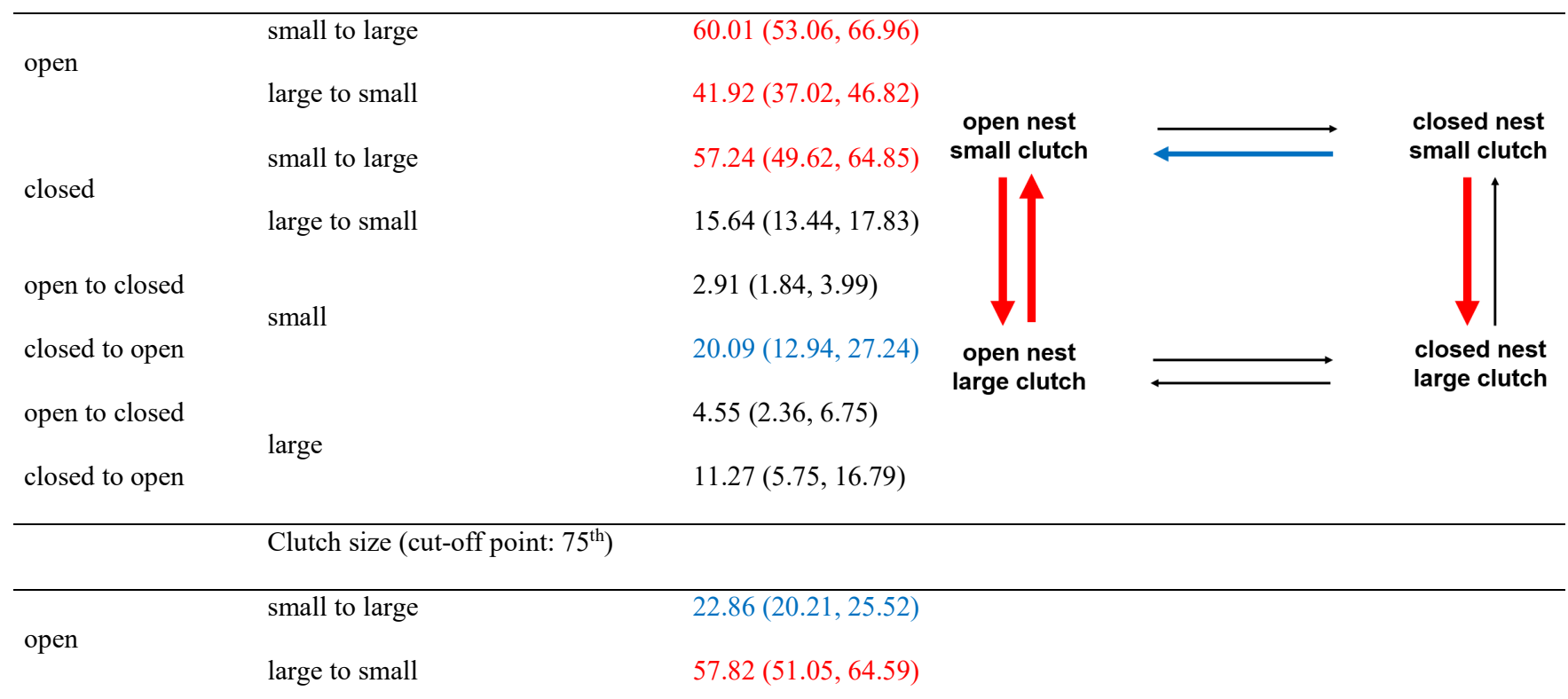




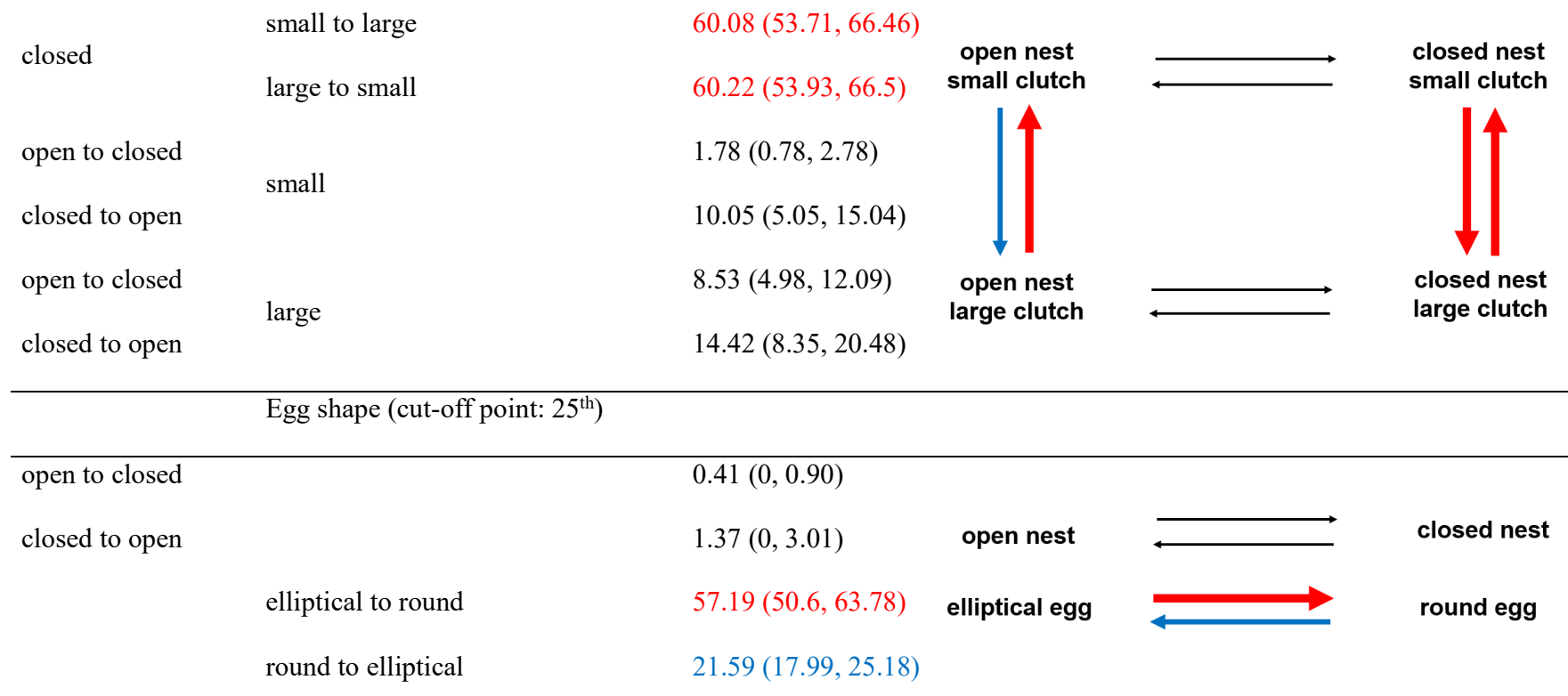

Egg shape (cut-off point: $50^{\text {th }}$ )

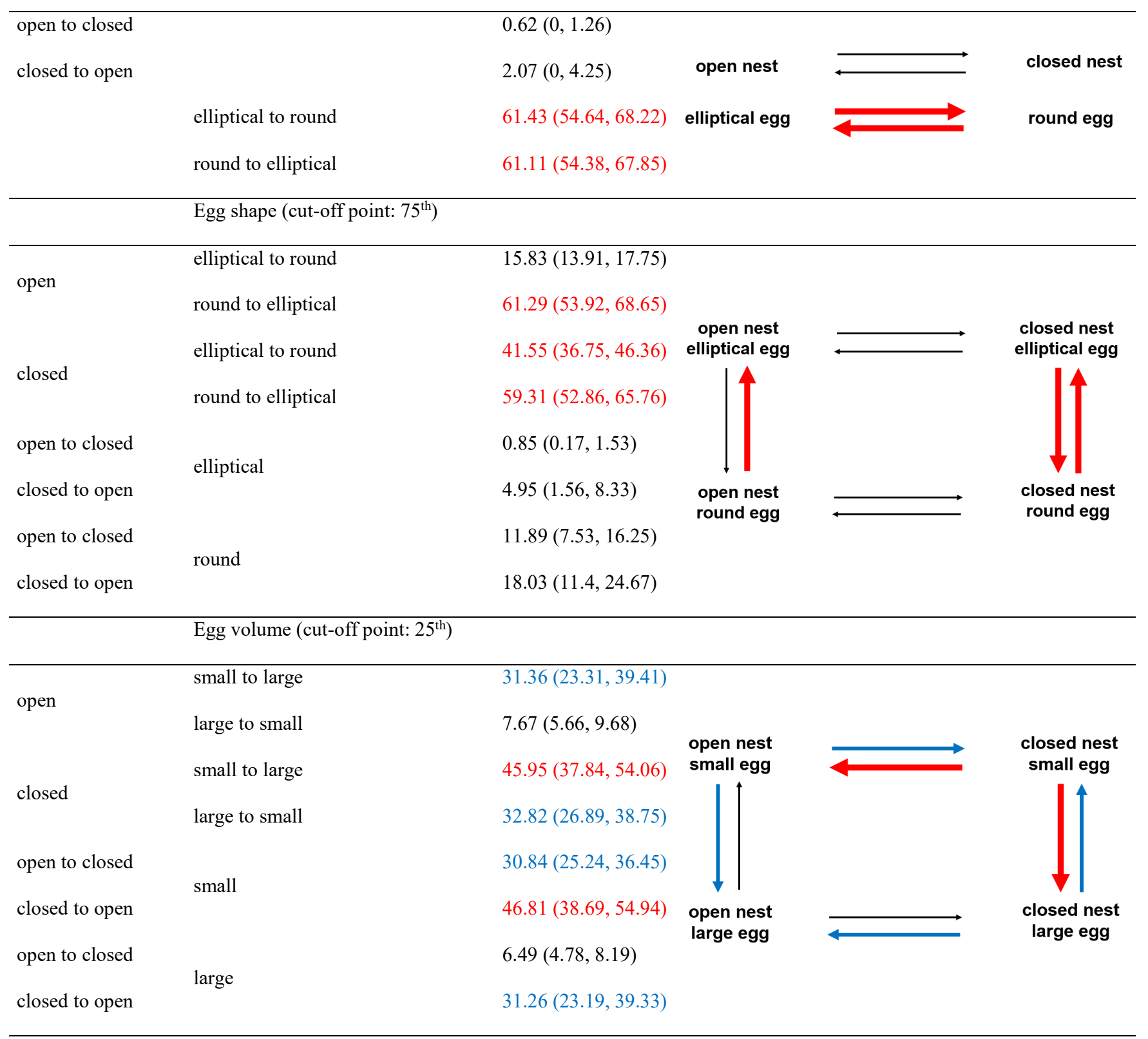

Egg volume (cut-off point: $50^{\text {th }}$ ) 


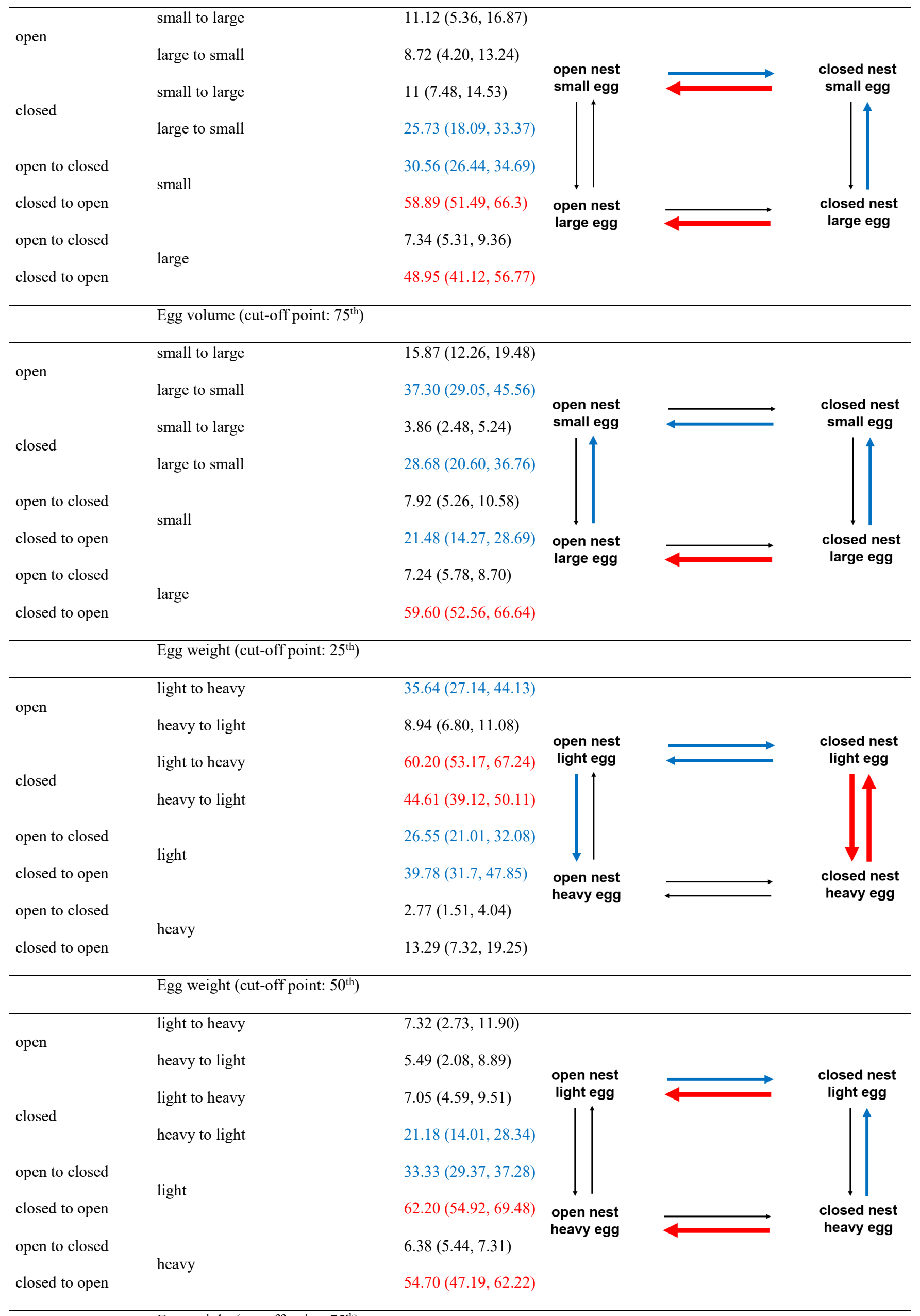

Egg weight (cut-off point: $75^{\text {th }}$ ) 


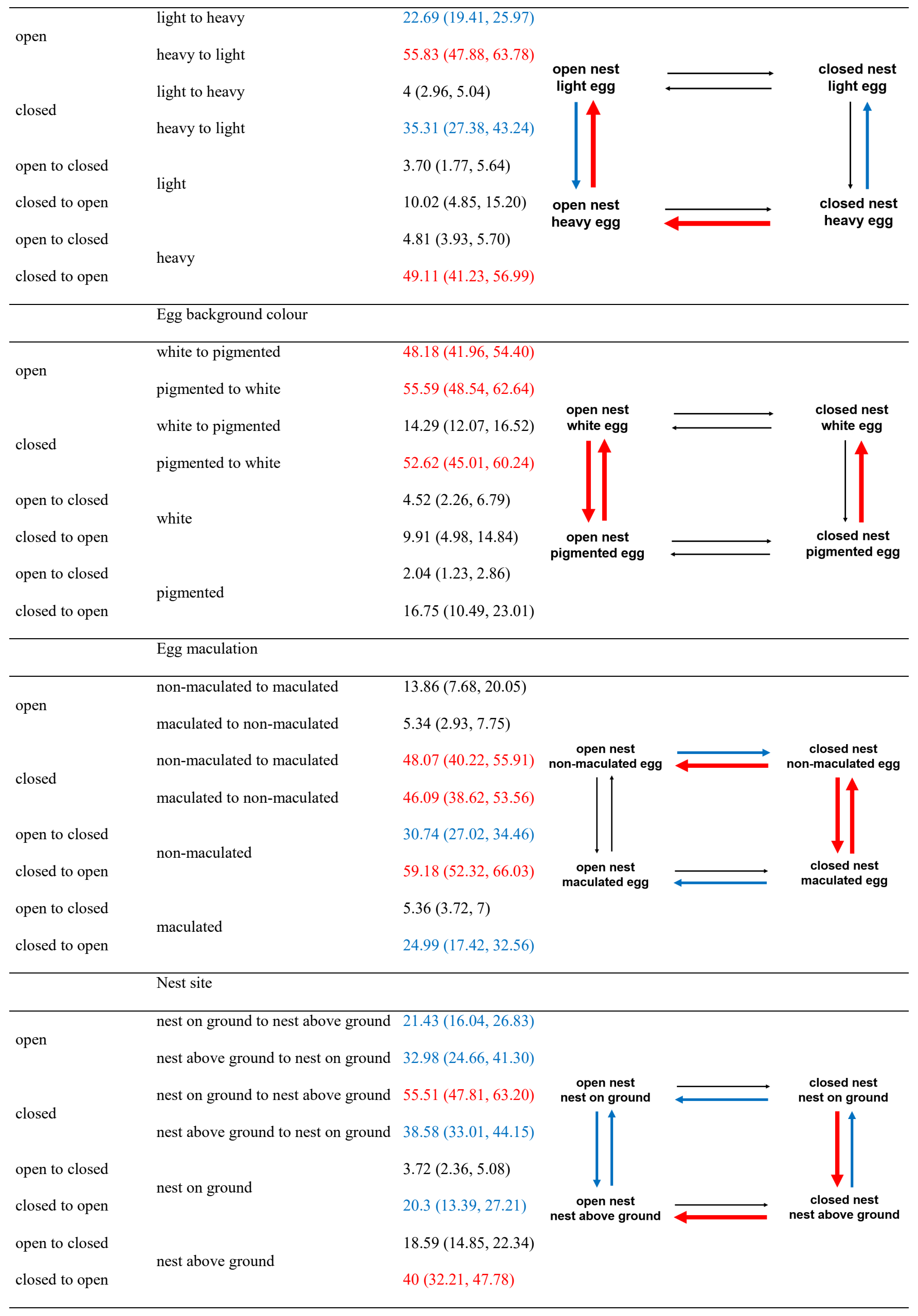


Table 4

\begin{tabular}{llllllllll}
\hline Scenario & Number of arrows & C & CICc & AIC & P & ACICc & L(g/data) & W \\
\hline scen1I2 & 5 & 5.948263 & 26.351933 & 36.837152 & 0.819591 & 0 & 1 & 0.188558538 \\
scen4G2 & 5 & 6.038506 & 26.442176 & 36.927395 & 0.812018 & 0.090243 & 0.955881335 & 0.180239587 \\
scen1I7 & 4 & 8.72095 & 27.05062 & 37.49729 & 0.726562 & 0.698687 & 0.705150869 & 0.132962217 \\
scen4G7 & 4 & 8.73056 & 27.060231 & 37.5069 & 0.725756 & 0.708298 & 0.701770396 & 0.1323248 \\
scen4H2 & 6 & 4.81445 & 27.299744 & 37.823726 & 0.777211 & 0.947811 & 0.622566082 & 0.11739015 \\
scen4H7 & 5 & 7.506504 & 27.910174 & 38.395393 & 0.676917 & 1.558241 & 0.458809357 & 0.086512421 \\
scen1L2 & 5 & 7.63803 & 28.0417 & 38.526919 & 0.664146 & 1.689767 & 0.429607405 & 0.081006144 \\
scen2A2 & 5 & 7.63803 & 28.0417 & 38.526919 & 0.664146 & 1.689767 & 0.429607405 & 0.081006144 \\
\hline
\end{tabular}

The summary of the best models $(\Delta \mathrm{CICc}<2)$ of phylogenetic path analyses containing egg shape as a predictor variable. Although scen 1 I 2 is the best model, scen 1 I 7 and scen $4 \mathrm{G} 7$ contain the most parsimonious connections because they contain the lowest number of arrows which represents fewer connections among variables and simpler scenarios. The summary of these scenarios is shown in Fig. 3A. 


\section{Table 5}

The summary of the best models $(\Delta \mathrm{CICc}<2)$ of phylogenetic path analyses containing egg volume as a predictor variable. Although scen4G2 is the best model, scen4G7 contains the most parsimonious connections with a similar weight because it contains the lowest number of arrows which represents fewer connections among variables and simpler scenarios. The summary of these scenarios is shown in Fig. $3 \mathrm{~B}$.

\begin{tabular}{|c|c|c|c|c|c|c|c|c|}
\hline Scenario & Number of arrows & $\mathrm{C}$ & $\mathrm{CICc}$ & $\mathrm{AIC}$ & $\mathrm{P}$ & $\Delta \mathrm{CICc}$ & $\mathrm{L}$ (g/data) & $\mathrm{W}$ \\
\hline scen4G2 & 5 & 2.966786 & 23.370455 & 33.855675 & 0.982195 & 0 & 1 & 0.282226392 \\
\hline scen4G7 & 4 & 5.653345 & 23.983015 & 34.429685 & 0.932539 & 0.61256 & 0.73618046 & 0.207769555 \\
\hline scen $4 \mathrm{H} 2$ & 6 & 2.177257 & 24.662551 & 35.186533 & 0.97509 & 1.292096 & 0.524112984 & 0.147918516 \\
\hline scen $1 \mathrm{I} 2$ & 5 & 4.271964 & 24.675634 & 35.160853 & 0.934245 & 1.305179 & 0.520695688 & 0.146954065 \\
\hline scen $4 \mathrm{H} 7$ & 5 & 4.863815 & 25.267485 & 35.752704 & 0.900088 & 1.89703 & 0.387315761 & 0.10931073 \\
\hline scen3E1 & 6 & 2.847086 & 25.332381 & 35.8563629 & 0.943584 & 1.961926 & 0.374949848 & 0.105820743 \\
\hline
\end{tabular}


Table 6

The summary of the best models $(\Delta \mathrm{CICc}<2)$ of phylogenetic path analyses containing egg background colour as a predictor variable. The first three scenarios have similar support because they are alternatives to each other but belong to distinct scenario families with different key factor (see supplementary 666 information for more detail). The summary of these scenarios is shown in Fig. 3C.

667

\begin{tabular}{llrrrrrrr}
\hline Scenario & Number of arrows & C & CICc & AIC & P & $\Delta$ CICc & L(g/data $)$ & W \\
& & & & & & \\
scen3I1 & 6 & 3.810475 & 26.293992 & 32.583956 & 0.873805 & 0 & 1 & 0.1407782 \\
scen1L1 & 6 & 3.810475 & 26.293992 & 36.81602 & 0.873805 & 0 & 1 & 0.1407782 \\
scen2A1 & 6 & 3.810475 & 26.293992 & 36.81602 & 0.873805 & 0 & 1 & 0.1407782 \\
scen1L3 & 5 & 6.749631 & 27.151825 & 37.63524 & 0.748851 & 0.857833 & 0.6512143 & 0.0916768 \\
scen3I3 & 5 & 6.766851 & 27.169045 & 33.435968 & 0.747257 & 0.875053 & 0.6456314 & 0.0908909 \\
scen2F1 & 6 & 5.411826 & 27.895342 & 38.417371 & 0.712788 & 1.60135 & 0.4490258 & 0.0632131 \\
scen2G1 & 6 & 5.453884 & 27.937401 & 38.45943 & 0.708144 & 1.643409 & 0.4396816 & 0.0618976 \\
scen1L2 & 5 & 7.777001 & 28.179195 & 38.66261 & 0.650609 & 1.885203 & 0.3896129 & 0.0548490 \\
scen2A2 & 5 & 7.777001 & 28.179195 & 38.66261 & 0.650609 & 1.885203 & 0.3896129 & 0.0548490 \\
scen3E1 & 6 & 5.718331 & 28.201848 & 34.491812 & 0.678749 & 1.907856 & 0.3852249 & 0.0542313 \\
scen1I1 & 6 & 5.744126 & 28.227642 & 38.749671 & 0.675869 & 1.93365 & 0.3802885 & 0.0535364 \\
scen4G1 & 6 & 5.782409 & 28.265926 & 38.787955 & 0.67159 & 1.971934 & 0.3730783 & 0.0525213 \\
\hline
\end{tabular}




\section{Table 7}

The summary of the best models $(\Delta \mathrm{CICc}<2)$ of phylogenetic path analyses containing egg maculation as a predictor variable. The first two scenarios have similar support because they are alternatives to each other but belong to distinct scenario families with different key factor (see supplementary information for more detail). The summary of these scenarios is shown in Fig. 3D.

\begin{tabular}{|c|c|c|c|c|c|c|c|c|}
\hline Scenario & Number of arrows & $\mathrm{C}$ & $\mathrm{cCIC}$ & AIC & $\mathrm{P}$ & $\overline{\Delta C I C c}$ & $\mathrm{~L}$ (g/data) & W \\
\hline scen1C2 & 5 & 5.444882 & 25.847076 & 36.330491 & 0.85955 & 0 & 1 & 0.0436953 \\
\hline scen2D2 & 5 & 5.444882 & 25.847076 & 36.330491 & 0.85955 & 0 & 1 & 0.0436953 \\
\hline scen4F2 & 5 & 5.446983 & 25.849177 & 36.332592 & 0.859392 & 0.002101 & 0.9989501 & 0.0436494 \\
\hline scen1L2 & 5 & 5.641711 & 26.043905 & 36.52732 & 0.844414 & 0.196829 & 0.9062732 & 0.0395999 \\
\hline $\operatorname{scen} 2 \mathrm{~A} 2$ & 5 & 5.641711 & 26.043905 & 36.52732 & 0.844414 & 0.196829 & 0.9062732 & 0.0395999 \\
\hline scen2E2 & 5 & 5.694418 & 26.096612 & 36.580027 & 0.84025 & 0.249536 & 0.8827017 & 0.0385699 \\
\hline $\operatorname{scen} 4 \mathrm{~A} 2$ & 5 & 5.694418 & 26.096612 & 36.580027 & 0.84025 & 0.249536 & 0.8827017 & 0.0385699 \\
\hline scen $1 \mathrm{C} 7$ & 4 & 8.187424 & 26.515891 & 36.960905 & 0.770318 & 0.668815 & 0.7157620 & 0.0312754 \\
\hline scen4F7 & 4 & 8.22093 & 26.549397 & 36.99441 & 0.767636 & 0.702321 & 0.7038708 & 0.0307558 \\
\hline scen1E2 & 5 & 6.204525 & 26.606718 & 37.090133 & 0.797797 & 0.759642 & 0.6839838 & 0.0298869 \\
\hline scen1L7 & 4 & 8.389189 & 26.717656 & 37.16267 & 0.754025 & 0.87058 & 0.6470770 & 0.0282742 \\
\hline scen $4 \mathrm{~A} 7$ & 4 & 8.468089 & 26.796556 & 37.24157 & 0.747565 & 0.94948 & 0.6220468 & 0.0271805 \\
\hline scen1N2 & 5 & 6.439922 & 26.842116 & 37.325531 & 0.777049 & 0.99504 & 0.6080367 & 0.0265683 \\
\hline scen $1 \mathrm{C} 1$ & 6 & 4.428052 & 26.911569 & 37.433598 & 0.816587 & 1.064493 & 0.5872842 & 0.0256616 \\
\hline scen2D1 & 6 & 4.428052 & 26.911569 & 37.433598 & 0.816587 & 1.064493 & 0.5872842 & 0.0256616 \\
\hline scen4F1 & 6 & 4.430153 & 26.91367 & 37.435698 & 0.81638 & 1.066594 & 0.5866675 & 0.0256346 \\
\hline scen3G1 & 6 & 4.473535 & 26.957051 & 33.247015 & 0.812075 & 1.109975 & 0.5740794 & 0.0250846 \\
\hline scen1L1 & 6 & 4.588425 & 27.071941 & 37.59397 & 0.800523 & 1.224865 & 0.5420308 & 0.0236842 \\
\hline $\operatorname{scen} 2 \mathrm{~A} 1$ & 6 & 4.588425 & 27.071941 & 37.59397 & 0.800523 & 1.224865 & 0.5420308 & 0.0236842 \\
\hline scen3I1 & 6 & 4.588425 & 27.071941 & 33.361905 & 0.800523 & 1.224865 & 0.5420308 & 0.0236842 \\
\hline scen2E1 & 6 & 4.641131 & 27.124648 & 37.646677 & 0.795153 & 1.277572 & 0.5279329 & 0.0230682 \\
\hline scen $4 \mathrm{~A} 1$ & 6 & 4.641131 & 27.124648 & 37.646677 & 0.795153 & 1.277572 & 0.5279329 & 0.0230682 \\
\hline scen3J1 & 6 & 4.691777 & 27.175293 & 33.465258 & 0.789954 & 1.328217 & 0.5147322 & 0.0224914 \\
\hline scen1E7 & 4 & 8.984777 & 27.313245 & 37.758258 & 0.70423 & 1.466169 & 0.4804248 & 0.0209923 \\
\hline scen $1 \mathrm{I} 2$ & 5 & 6.94753 & 27.349724 & 37.833139 & 0.730389 & 1.502648 & 0.4717416 & 0.0206129 \\
\hline scen4C2 & 6 & 4.876613 & 27.360129 & 37.882158 & 0.770679 & 1.513053 & 0.4692937 & 0.0205059 \\
\hline scen2L2 & 5 & 7.032302 & 27.434496 & 37.917911 & 0.722392 & 1.58742 & 0.4521642 & 0.0197574 \\
\hline
\end{tabular}




\begin{tabular}{clllllllll} 
scen4G2 & 5 & 7.061799 & 27.463993 & 37.947408 & 0.719598 & 1.616917 & 0.4455443 & 0.0194682 \\
scen1J2 & 5 & 7.074809 & 27.477002 & 37.960417 & 0.718364 & 1.629926 & 0.4426557 & 0.0193420 \\
scen4B2 & 5 & 7.096538 & 27.498732 & 37.982147 & 0.716301 & 1.651656 & 0.4378723 & 0.0191330 \\
scen1N7 & 4 & 9.219899 & 27.548366 & 37.99338 & 0.684042 & 1.70129 & 0.4271393 & 0.0186640 \\
scen1C3 & 5 & 7.211821 & 27.614015 & 38.09743 & 0.705308 & 1.766939 & 0.4133463 & 0.0180613 \\
scen4F3 & 5 & 7.243493 & 27.645686 & 38.129102 & 0.702275 & 1.79861 & 0.4068523 & 0.0177775 \\
scen3G3 & 5 & 7.257303 & 27.659497 & 33.926421 & 0.700951 & 1.812421 & 0.4040525 & 0.0176552 \\
scen1E1 & 6 & 5.187695 & 27.671211 & 38.19324 & 0.73734 & 1.824135 & 0.4016929 & 0.0175521 \\
scen2G2 & 5 & 7.287853 & 27.690047 & 38.173462 & 0.698019 & 1.842971 & 0.3979275 & 0.0173876 \\
scen2F2 & 5 & 7.338498 & 27.740692 & 38.224107 & 0.693149 & 1.893616 & 0.3879775 & 0.0169528 \\
scen1L3 & 5 & 7.372193 & 27.774387 & 38.257802 & 0.689902 & 1.927311 & 0.3814958 & 0.0166696 \\
scen3I3 & 5 & 7.401764 & 27.803958 & 34.070882 & 0.687049 & 1.956882 & 0.3758967 & 0.0164249 \\
\hline
\end{tabular}


Figure 1. (A) The ancestral state estimation of nest design in 598 species of birds. Both the Bayesian trait estimation and the stochastic character mapping have the same results, i.e. the semi-open design of nests was the most probable ancestral type. (B) The ancestral state estimation of nest site in 598 species of birds. Nesting on the ground was the most probable ancestral nest site and this trait could have evolved dependently with nest design (Table 2 and 3). Changes in the colours represent possible transitions among the categories of nest design and nest site through the evolution of these birds. The numbers show the estimated time intervals in million years.

Figure 2. (A) The ancestral state estimation of egg shape in 588 species of birds. The ancestral egg shape could be either round or elliptic and this trait could have evolved dependently with nest design (Table 2 and 3). Changes in the colours from blue to red represent possible transitions in egg shape through the evolution of these birds. (B) The ancestral state estimation of egg background colour in 592 species of birds. The ancestral background colour of egg could be white (or either white or pigmented, see Supplementary table 11). (C) The ancestral estimation of egg maculation in 592 species of birds. Egg maculation could have evolved multiple times and very early during the evolution of birds. Changes in the colours represent possible transitions among the categories of egg background colour and egg maculation through the evolution of these birds. The numbers show the estimated time intervals in million years.

Figure 3. The influence of parental body mass (BM), nest site (NS), clutch size (CS), and egg characteristics on nest design (ND) in 556 species of birds. Black ellipse is the final destination, arrows indicate the direction among steps. Line thickness corresponds to the number of paths, in which the connection is presented (see Table 4 to 7 for detail), numbers are the cumulative weights of the scenarios containing that arrow (importance of connection). The size of the arrowheads indicates the strength of the direction. A egg shape (ES), B - egg volume (EV), C - egg background colour (EC), D - egg maculation (EM). 


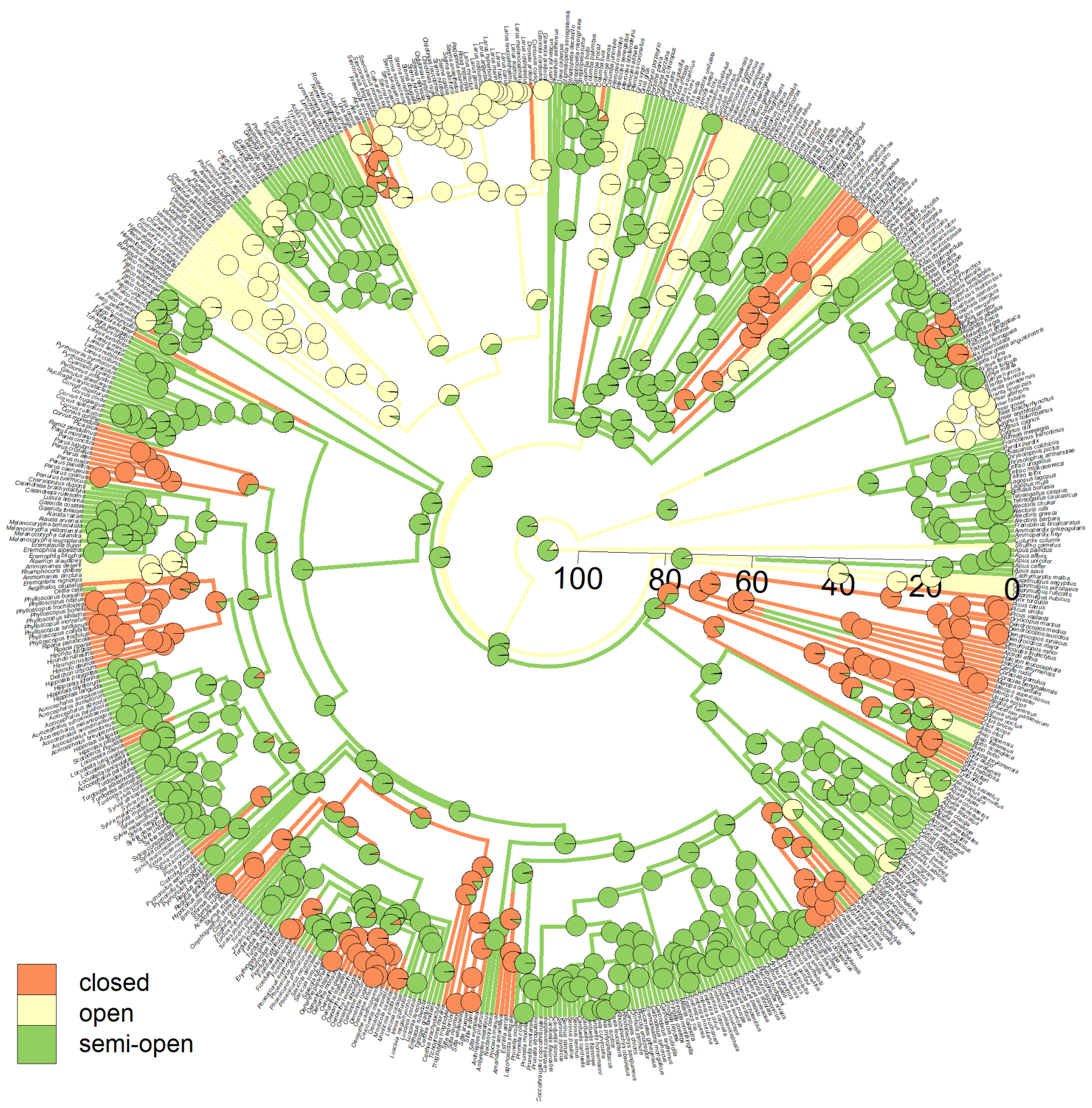




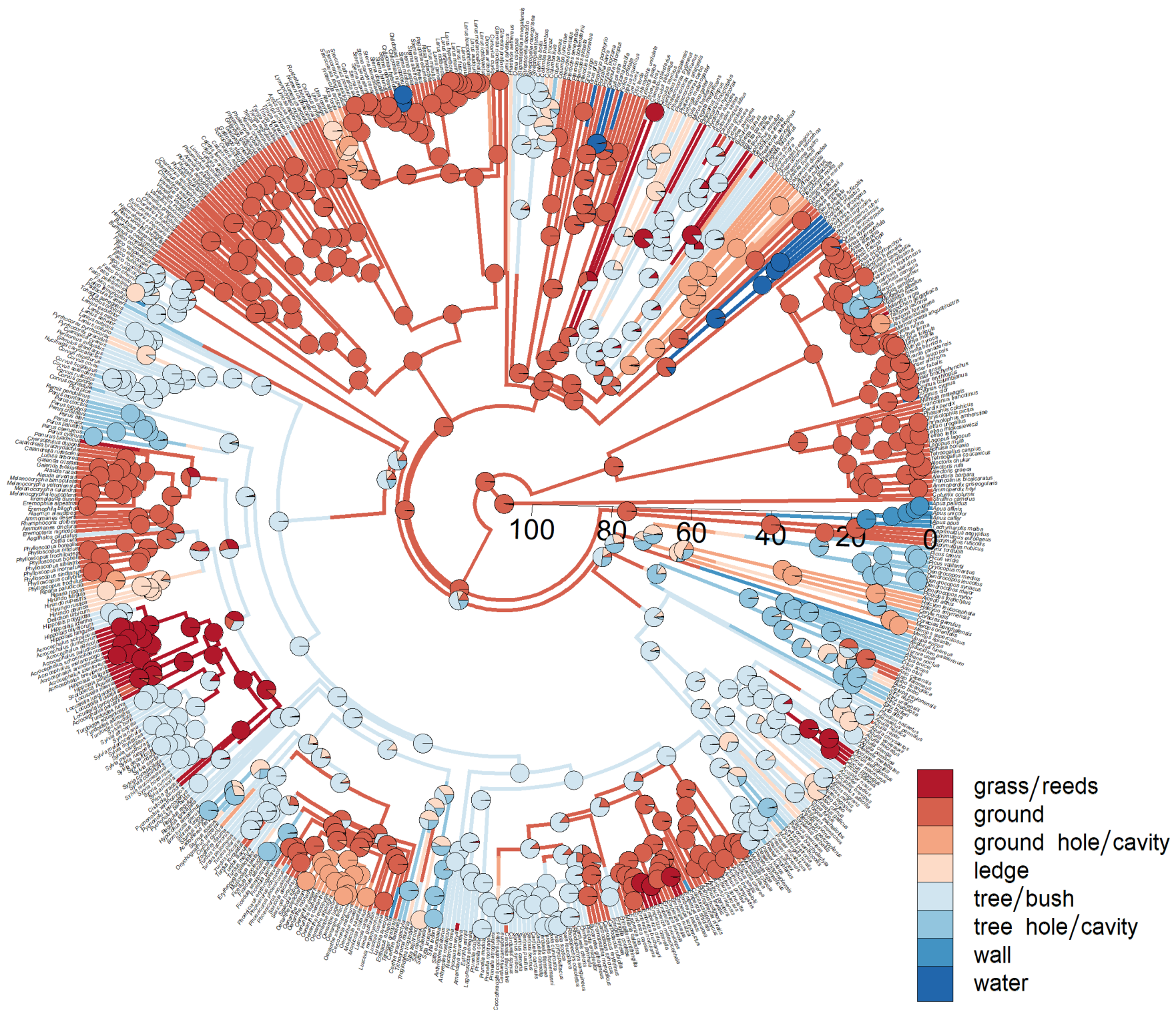


Figure 2A

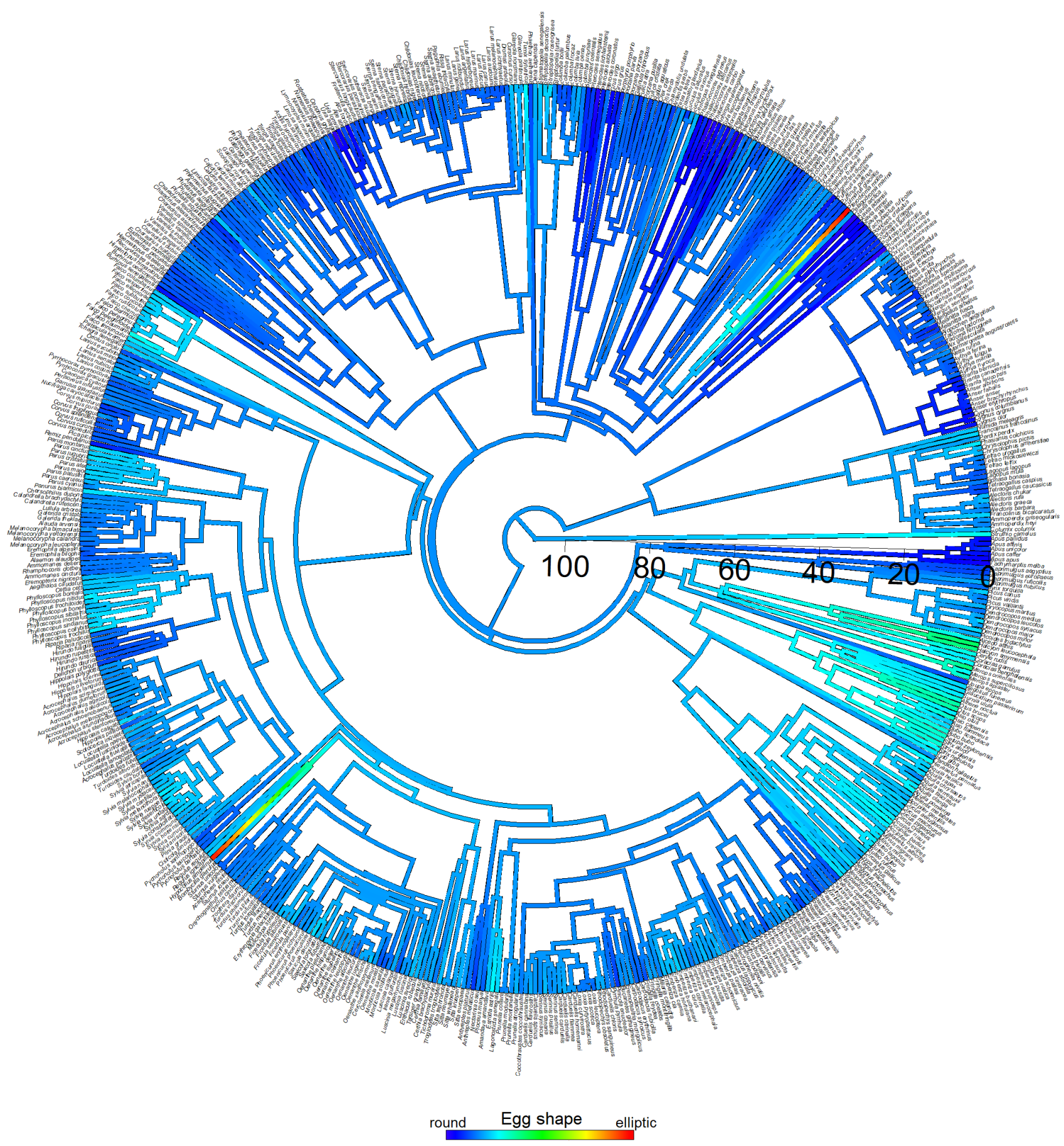




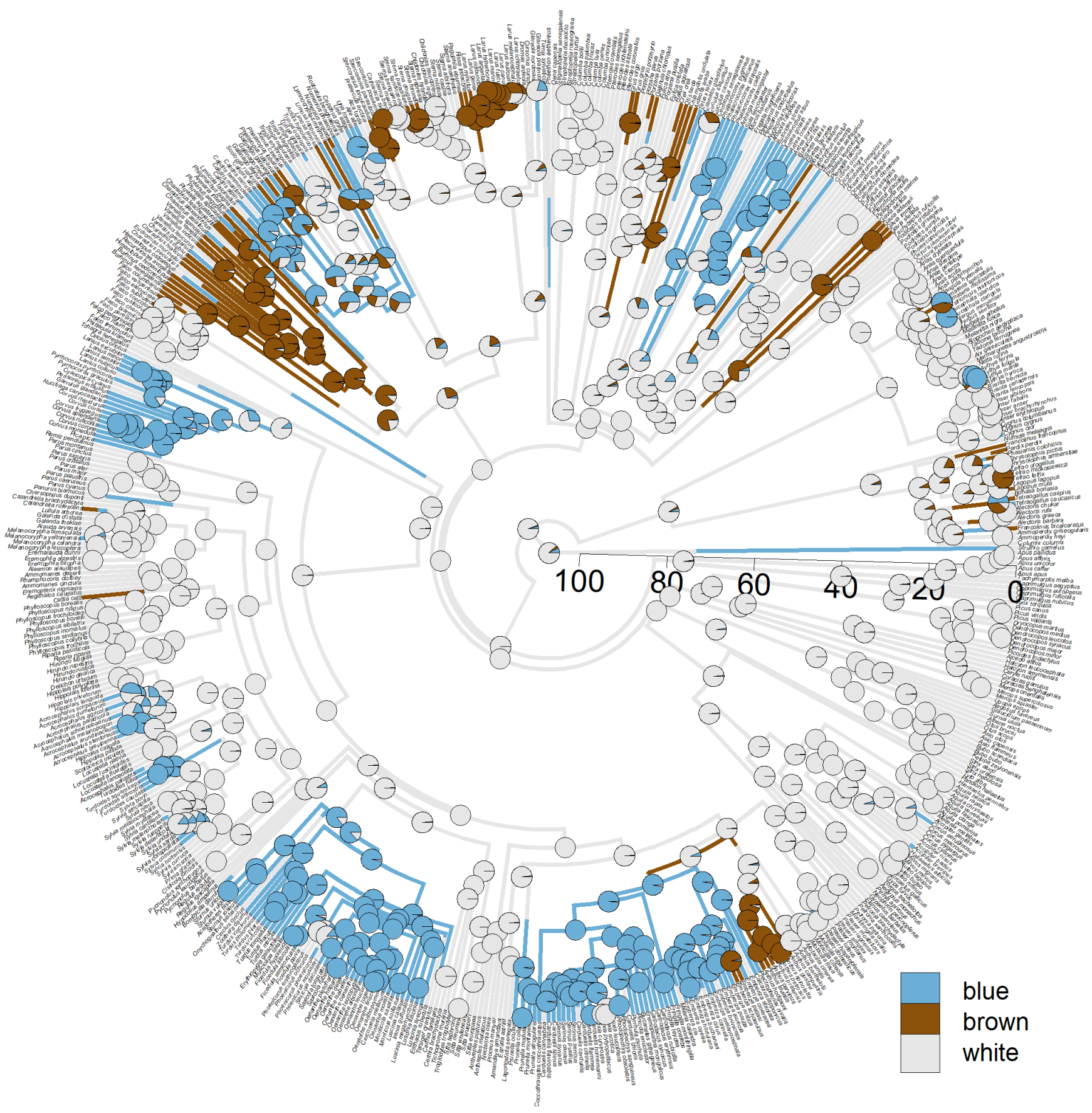




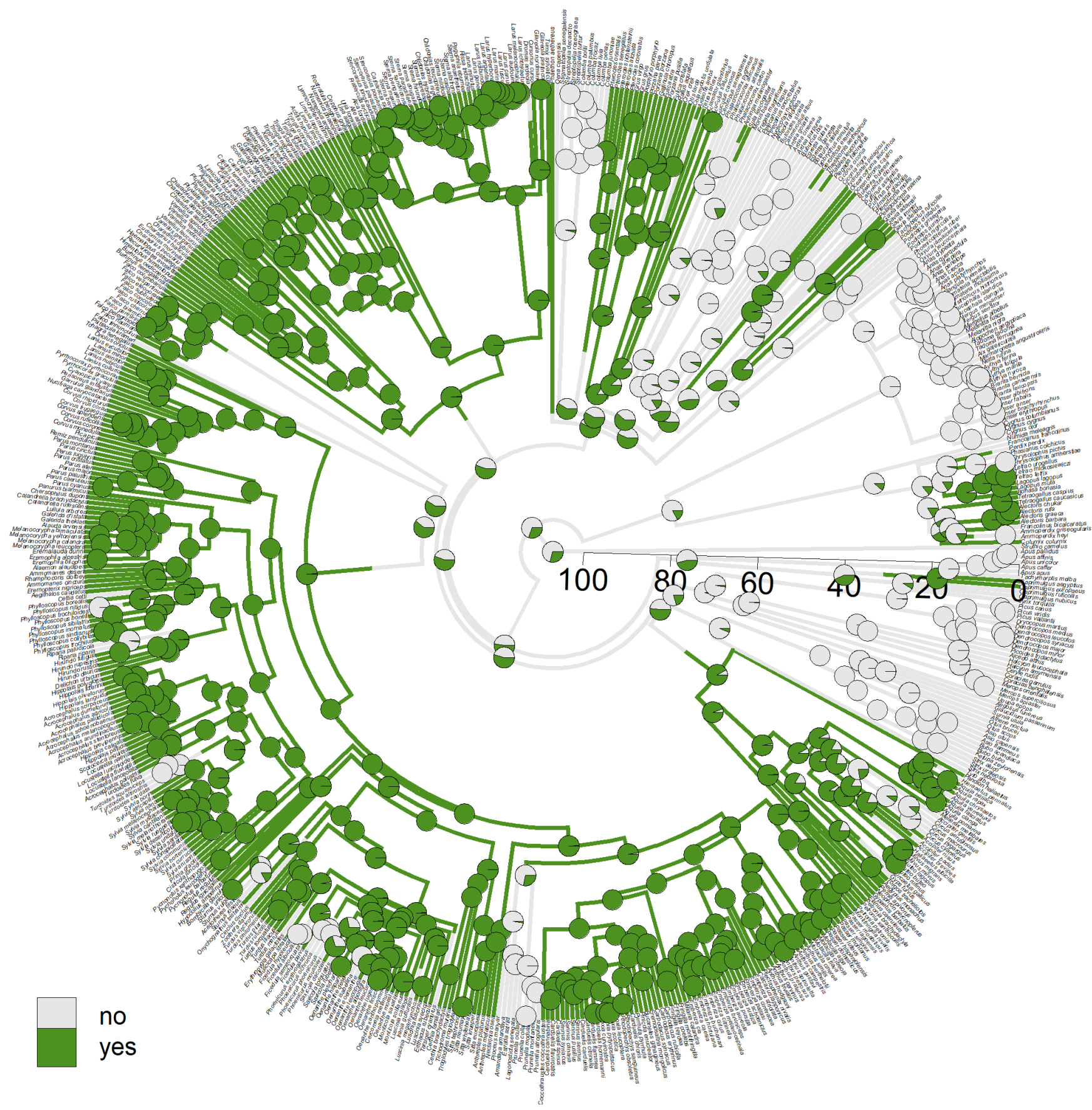




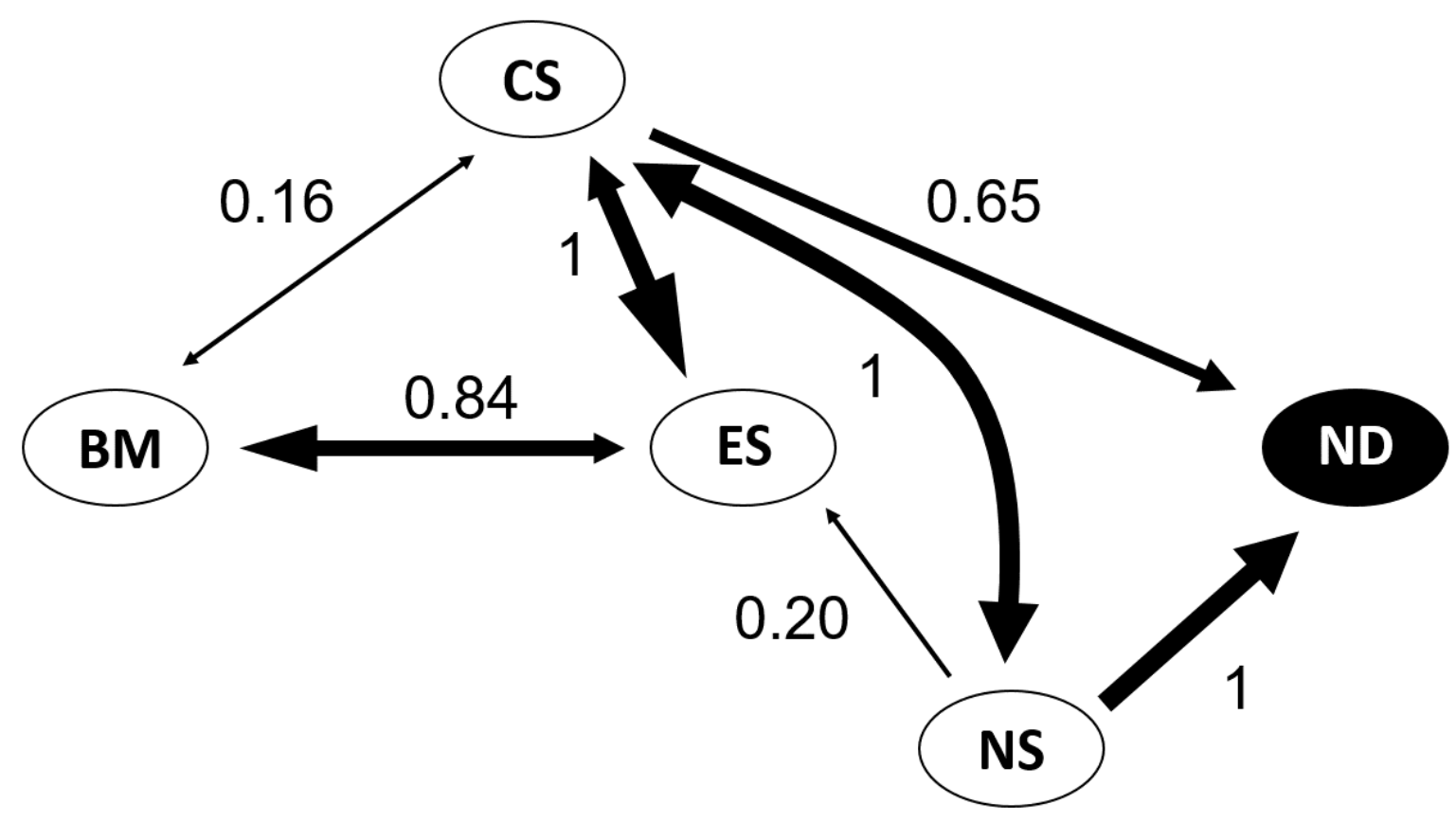




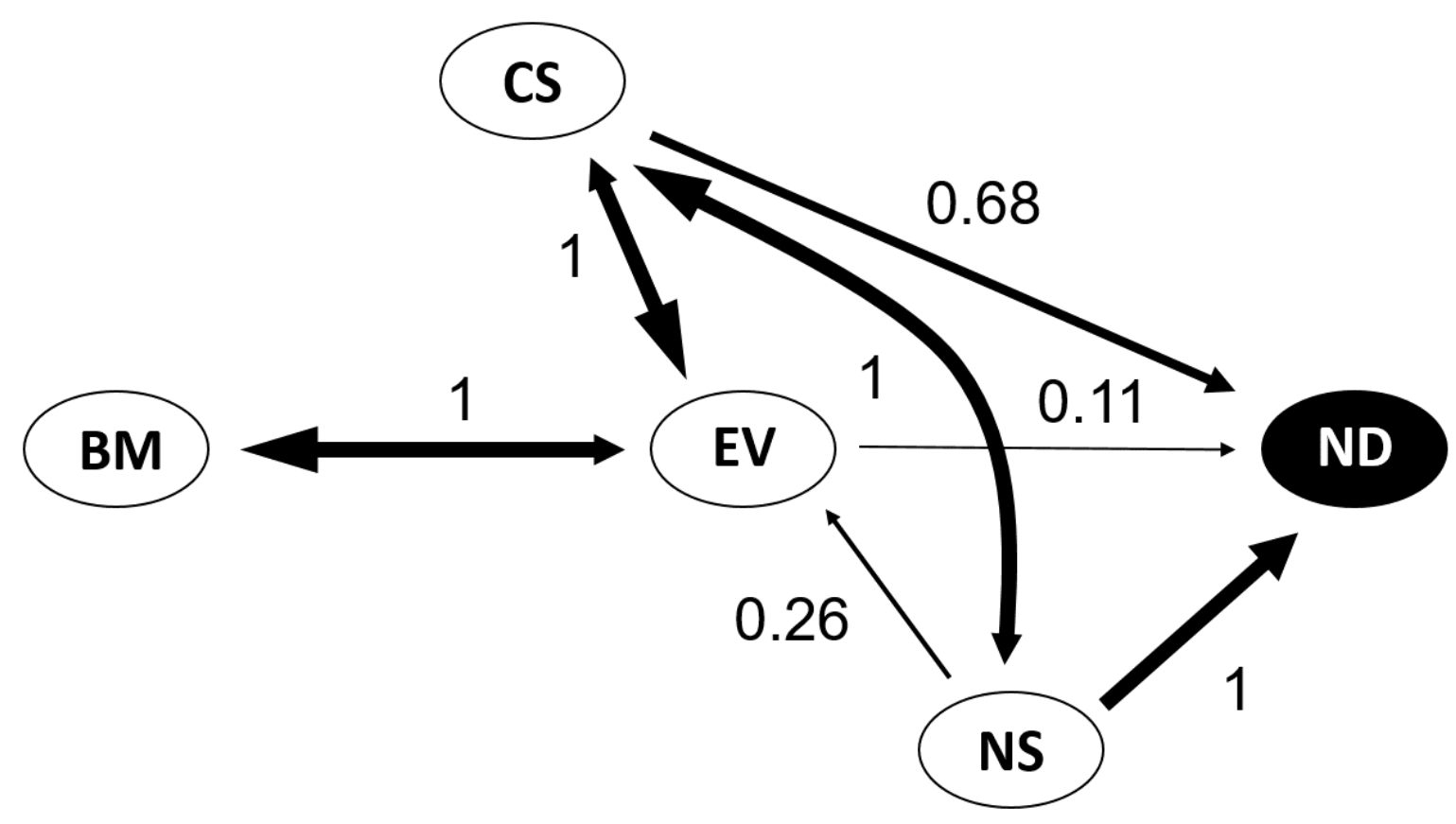




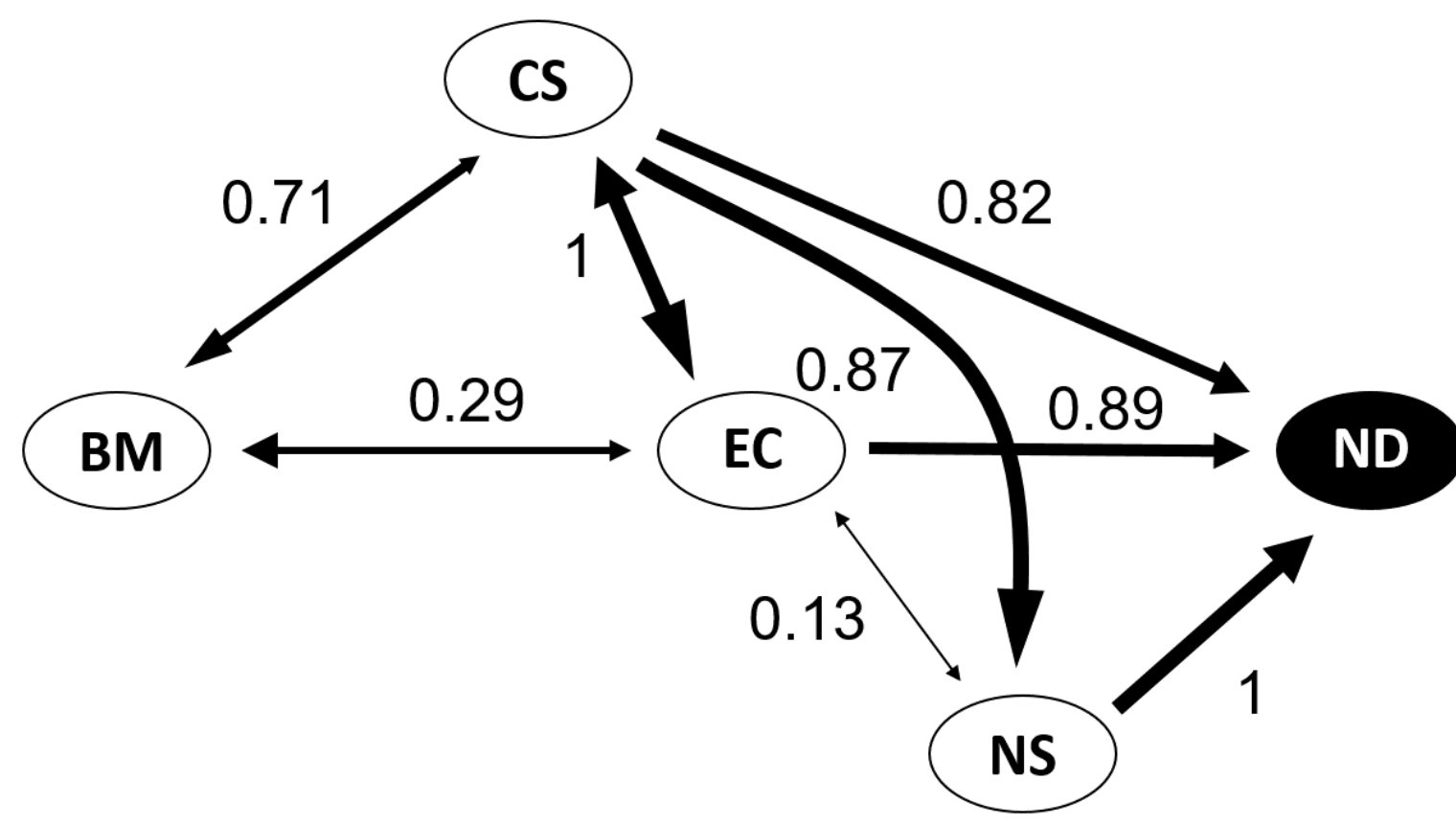




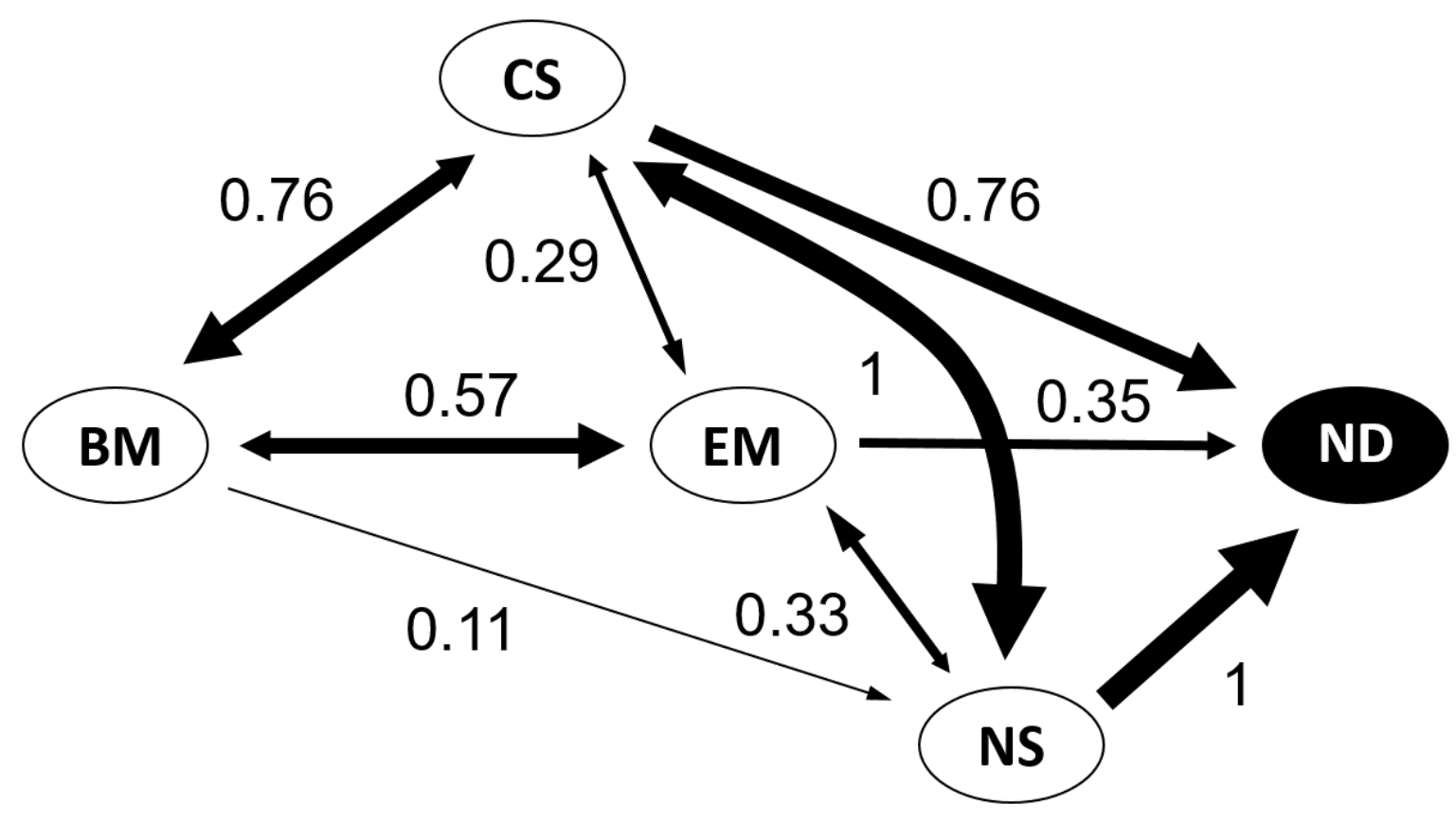

